\title{
Soil Moisture Data for the Validation of Permafrost Models Using Direct and Indirect Measurement Approaches at Three Alpine Sites
}

\author{
Cécile Pellet *, Christin Hilbich, Antoine Marmy and Christian Hauck \\ Department of Geosciences, University of Fribourg, Fribourg, Switzerland
}

In regions affected by seasonal and permanently frozen conditions soil moisture influences the thermal regime of the ground as well as its ice content, which is one of the main factors controlling the sensitivity of mountain permafrost to climate changes. In this study, several well established soil moisture monitoring techniques were combined with data from geophysical measurements to assess the spatial distribution and temporal evolution of soil moisture at three high elevation sites with different ground properties and thermal regimes. The observed temporal evolution of measured soil moisture

OPEN ACCESS

Edited by:

Annett Bartsch,

Zentralanstalt für Meterologie und

Geodynamik, Austria

Reviewed by:

Christian Beer,

Stockholm University, Sweden

Ketil Isaksen,

Norwegian Meteorological Institute,

Norway

${ }^{*}$ Correspondence:

Cécile Pellet

cecile.pellet@unifr.ch

Specialty section:

This article was submitted to

Cryospheric Sciences,

a section of the journal

Frontiers in Earth Science

Received: 07 October 2015 Accepted: 16 December 2015

Published: 07 January 2016

Citation:

Pellet C, Hilbich C, Marmy A and Hauck C (2016) Soil Moisture Data for the Validation of Permafrost Models

Using Direct and Indirect Measurement Approaches at Three Alpine Sites. Front. Earth Sci. 3:91.

doi: 10.3389/feart.2015.00091 is characteristic for sites with seasonal freeze/thaw cycles and consistent with the respective site-specific properties, demonstrating the general applicability of continuous monitoring of soil moisture at high elevation areas. The obtained soil moisture data were then used for the calibration and validation of two different model approaches used in permafrost research in order to characterize the lateral and vertical distribution of ice content in the ground. Calibration of the geophysically based four-phase model (4PM) with spatially distributed soil moisture data yielded satisfactory two dimensional distributions of water-, ice-, and air content. Similarly, soil moisture time series significantly improved the calibration of the one-dimensional heat and mass transfer model COUP, yielding physically consistent soil moisture and temperature data matching observations at different depths.

Keywords: mountain permafrost, soil moisture, permafrost modeling, Electrical Resistivity Tomography (ERT), four-phase model

\section{INTRODUCTION}

Soil moisture is a key factor controlling the energy and mass exchange processes at the soilatmosphere interface. Ranging from local to global scale, it can for example influence air temperature and humidity as well as precipitation regimes, the occurrence of heat waves and droughts, the water availability for plants or the stability of mountain slopes (for a review see Seneviratne et al., 2010). Therefore, soil moisture was classified in 2010 as an Essential Climate Variable (ECV) by the Global Climate Observing System (GCOS).

In regions affected by seasonal and permanent frozen conditions soil moisture is of particular relevance. It influences the physical properties of the subsurface (e.g., ice content, thermal conductivity, heat capacity, hydraulic conductivity, electrical conductivity, and permittivity), the energy and water exchange processes with the atmosphere (e.g., changing albedo, evaporation, 
infiltration rates, refreezing rates, latent heat release, ground heat flux, runoff, Hinkel et al., 2001; Boike et al., 2003, 2008; Westermann et al., 2009, 2011; Scherler et al., 2010) and the characteristics of different permafrost landforms (e.g., differences of the above for soil, bedrock, rock glacier with coarse-or finegrained blocky material, talus slopes, steep, or flat terrain, Rist and Phillips, 2005).

Despite its importance, its high spatial and temporal variability (Brocca et al., 2010) and the technical challenges inherent to the measurements prevented the soil moisture from being measured operationally at large scales. Numerous independent soil moisture monitoring networks currently exist all around the world but they need to be harmonized and qualitatively assessed. The efforts made in that direction lead to the creation of the International Soil Moisture Network (Dorigo et al., 2011) and before that the global soil moisture data bank (Robock et al., 2000).

In mountainous terrains remote sensing approaches (e.g., Kerr et al., 2001, 2010; Entekhabi et al., 2010) are most often not applicable. Due to their coarse resolution and the complex retrieval algorithms for the signals in steep topographic terrains, they are unable to capture the true soil moisture in regions with pronounced topography that changes over small spatial scale. Furthermore, the in situ soil moisture measurements necessary for the validation of remote sensing products (e.g., Albergel et al., 2011; Bircher et al., 2012; Rautiainen et al., 2012; Magagi et al., 2013) are also sparse in these areas, since measurements in mountainous terrains are costly to implement and were so far not in the focus of climatic studies. Although, the influence of soil moisture on the thermal regime of frozen ground was confirmed in many modeling studies (e.g., Hinkel et al., 2001; Boike et al., 2008; Westermann et al., 2009; Scherler et al., 2010) soil moisture measurements remain restricted to uncoordinated and project based installations (e.g., Hilbich et al., 2011; Rist and Phillips, 2005). Globally, there is a large data gap in terms of spatial and temporal soil moisture data at high elevation that needs to be filled.

To capture the spatial variations of soil moisture geophysical methods such as Electrical Resistivity Tomography (ERT) (e.g., Hauck, 2002; Brunet et al., 2010; Hilbich et al., 2011; Calamita et al., 2012) and ground penetrating radar (GPR) (e.g., Westermann et al., 2010; Wollschlaeger et al., 2010) are the most suitable and widely applied techniques in mountainous terrains. ERT is particularly sensitive to phase changes between unfrozen water and ice and is therefore among the most commonly used methods in permafrost research for the characterization of subsurface properties (e.g., Hauck and Kneisel, 2008; Kneisel et al., 2008; Hauck, 2013). However, the quantification of ice, water and air content in the ground is not possible from the interpretation of the profiles alone. It requires either some additional information such as borehole temperature and stratigraphic data (e.g., Arenson et al., 2002; Monnier and Kinnard, 2013), and/or borehole geophysical datasets (e.g., Scapozza et al., 2014; Vonder Mühll and Holub, 1992) or using combinations of geophysical data (e.g., Monnier et al., 2011; Hausmann et al., 2012).
More particularly, applied in combination with Refraction Seismic Tomography (RST), the ERT technique can be used to quantitatively assess the different phase contents (water, ice, and air) in the ground (Hauck et al., 2008, 2011; Schneider et al., 2013).

For the in situ measurements of soil moisture and its temporal evolution numerous well established direct and indirect methods are available (e.g., Hillel, 2004; Robinson et al., 2008; Vereecken et al., 2008). Among them only few were tested in terrains undergoing seasonal or permanent frozen conditions. The frequency domain reflectometry (FDR) and time domain reflectometry (TDR) sensors are proven to be effective in such conditions (e.g., Roth and Boike, 2001; Rist and Phillips, 2005; Hilbich et al., 2011).

Within the framework of the SNSF-project SOMOMOUNT (Soil moisture in mountainous terrain and its influence on the thermal regime in seasonal and permanently frozen terrains), a network of six entirely automated soil moisture stations was installed in Switzerland along an altitudinal gradient ranging from $1200 \mathrm{~m}$. a.s.l. to $3400 \mathrm{~m}$. a.s.l. and designed to complement the existing low altitude soil moisture monitoring network located on the Swiss plateau, SwissSMEX (Mittelbach et al., 2011). These stations were coupled (wherever possible) with already existing permafrost monitoring stations. The standard instrumentation of each soil moisture station comprises gravimetric soil sampling and the installation of Frequency Domain Reflectometry (FDR) and Time Domain Reflectometry (TDR) sensors for long term monitoring. Additionally, repeated geophysical surveys (ERT, RST) as well as spatial FDR (S-FDR) measurements are performed to assess the two dimensional spatial distribution of soil moisture in the ground.

Using this comprehensive dataset we develop a methodology to link the various methods and use the resulting dataset to calibrate and validate two types of model approaches, which are currently used in permafrost research: (1) the geophysically based four-phase model (4PM) (Hauck et al., 2011), that combines ERT and RST measurements to quantify the spatial variability of ice, water, and air content in the near subsurface (down to $10-30 \mathrm{~m})$ and (2) the coupled heat and mass transfer model (COUP) (Jansson and Moon, 2001; Jansson, 2012), that uses atmospheric forcing as input to reconstruct the entire energy and water balance for one soil column. The COUP model is currently used in permafrost research for process modeling and long-term transient modeling of the permafrost evolution (Scherler et al., 2010, 2013, 2014) as well as for sensitivity studies (Engelhardt et al., 2010; Marmy et al., 2013; Staub et al., 2015), whereas the $4 \mathrm{PM}$ was selected for its ability to determine the spatial variability of ice content in the ground, which was found to be one of the key factors controlling the sensitivity of mountain permafrost to climate changes (e.g., Harris et al., 2009; Scherler et al., 2013).

In this paper our objectives are (1) to develop and test a standard methodology to coherently quantify the temporal evolution and the two dimensional distribution of soil moisture at high elevation using direct and indirect measurement techniques and (2) use the collected datasets to calibrate and validate two model types used in permafrost research, 4PM and COUP. 


\section{METHODS}

The investigation of the temporal evolution and spatial distribution of soil moisture cannot be achieved using only one method. Therefore, we developed a methodology, which combines several well established methods to produce reliable spatial and temporal measurements in seasonally and permanently frozen areas (Figure 1). These data were then used to calibrate the $4 \mathrm{PM}$ and validate the COUP model, which are used to assess the ground ice content as final goal.

\section{Measurement Approaches}

First, soil samples were collected and used as ground truth for the calibration of the other (indirect) methods. Secondly, frequency domain reflectometry (FDR) based sensors were installed down to $50 \mathrm{~cm}$ depth for long-term monitoring purposes. Thirdly, spatial-FDR (S-FDR) and geophysical methods [(automatic) electrical resistivity tomography ((A-)ERT) and refraction seismic tomography (RST)] were used for the determination of the spatial distribution of soil moisture and the quantification of the ice content. Figure 1 summarizes the methods and their inter-dependency. This methodology was tested at three highaltitude field sites selected for their data availability (the longest and most complete time series among the SOMOMOUNT network) and their various subsurface properties: Schilthorn, Cervinia and Gemmi (Figure 2 and Table 1).

\section{Soil Samples}

Soil sampling is the only direct method available to measure the unfrozen water content in the ground. In this study, samples of known volume were collected at each site using standard measurement cylinders and a hand auger. The soil samples were collected in the vicinity of each soil moisture monitoring sensor at corresponding depths.

Following the standard gravimetric method the samples were weighted and oven dried at $105^{\circ} \mathrm{C}$ during $24 \mathrm{~h}$ for the mineral soils and $60^{\circ} \mathrm{C}$ during $48 \mathrm{~h}$ for organic soils. The dry samples were then weighted to determine the gravimetric water content

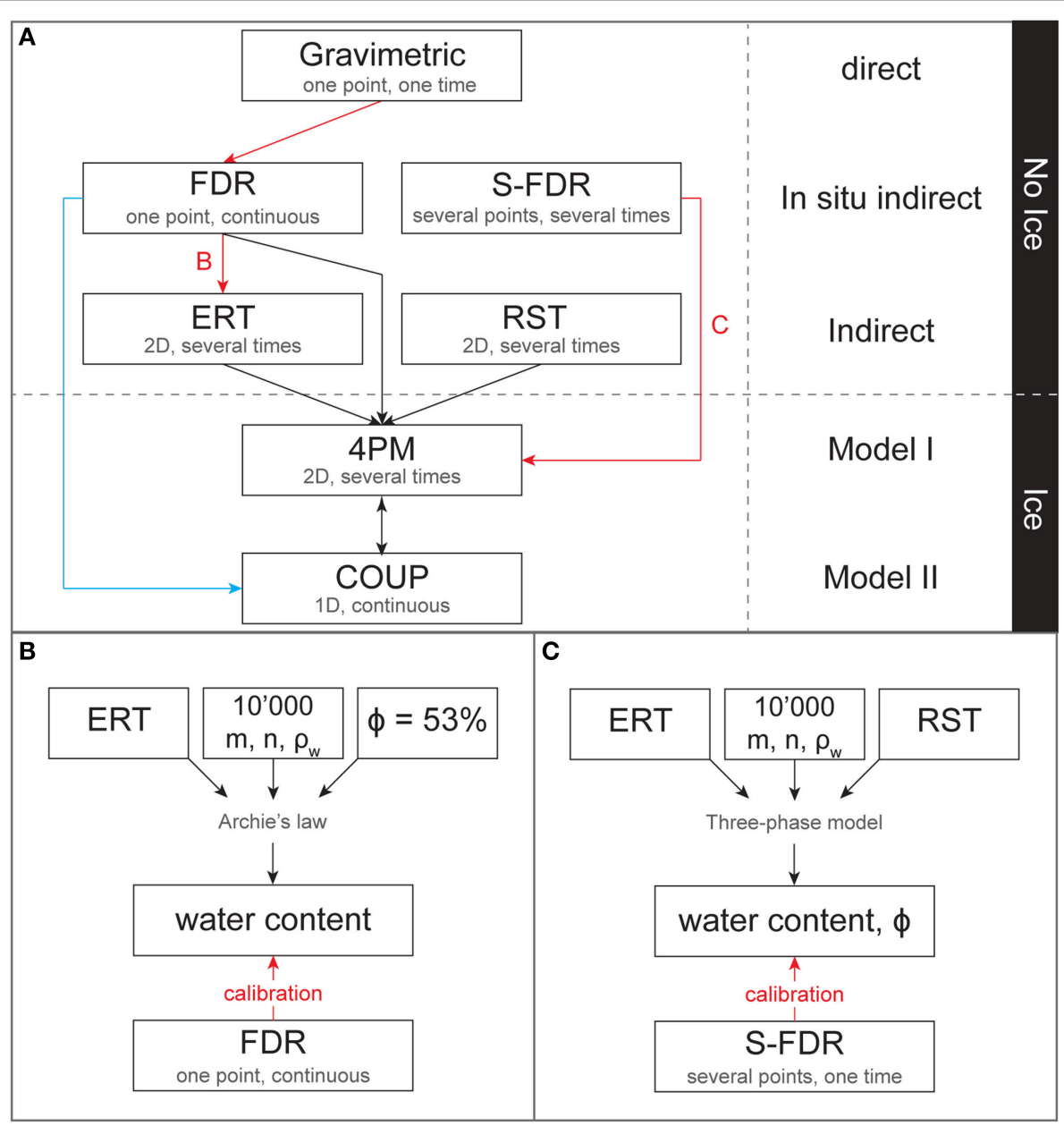

FIGURE 1 | (A) Schematics of the overall methodological concept and set of methods applied to assess water content. The red arrows represent calibration process, the blue the validation process. The specific calibration procedure for (B) Archie's law and (C) the 4PM are also shown. The number 10,000 indicates hereby the number of random combinations of the Archie parameters $\mathrm{m}, \mathrm{n}$ and the pore water resistivity $\rho_{\mathrm{W}} . \Phi$ is the porosity, taken from Scherler (2006) in B and calibrated in C. 


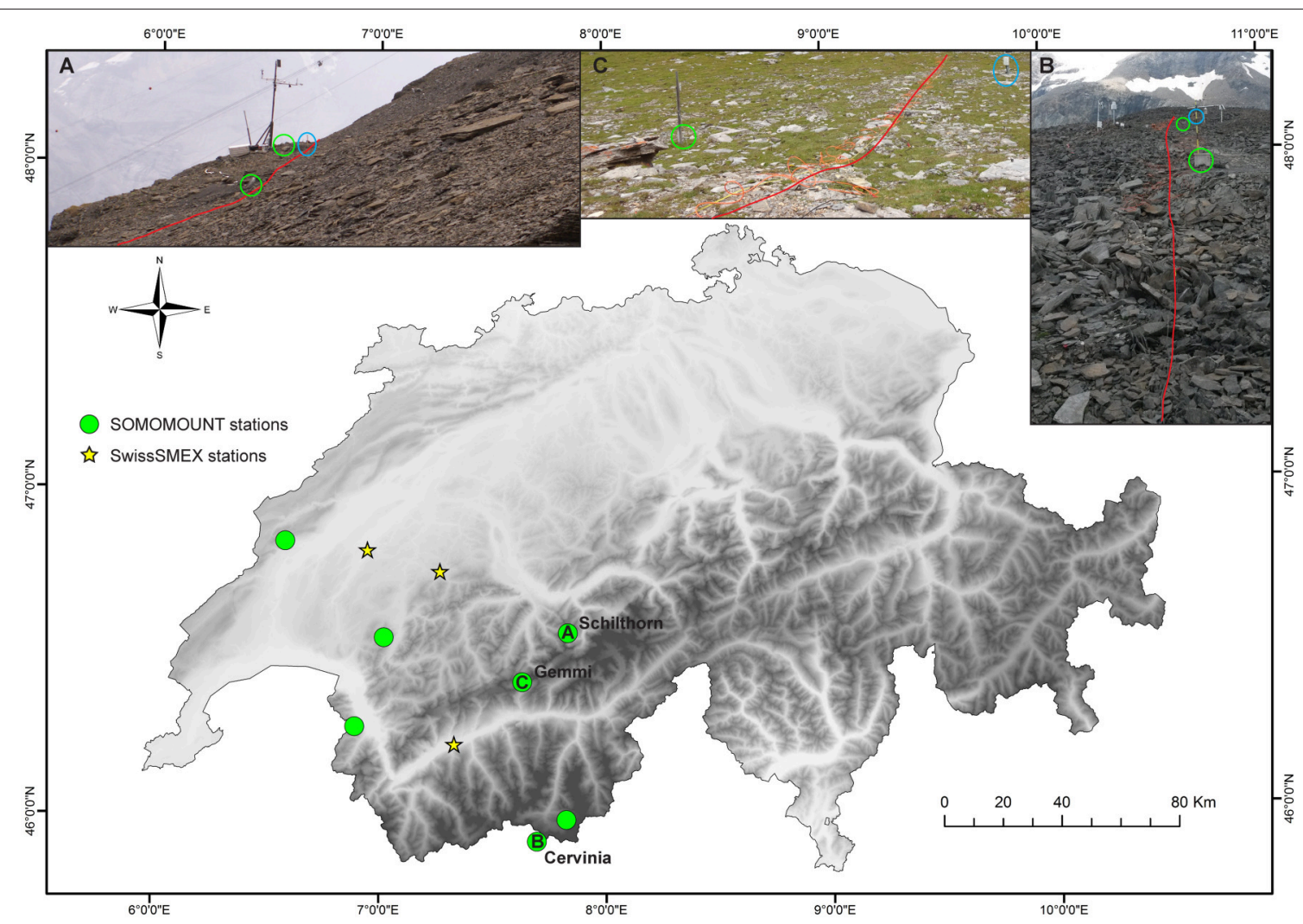

FIGURE 2 | Location of the three field sites and overview of the geophysical profiles (red lines), borehole locations (green), and soil moisture monitoring stations (blue) at (A) Schilthorn, (B) Cervinia, and (C) Gemmi. The digital elevation model was obtained from Bundesamt für Landestopografie swisstopo.

TABLE 1 | Summary of the relevant data available at Schilthorn, Cervinia, and Gemmi.

\begin{tabular}{|c|c|c|c|c|c|c|}
\hline Station & Gravimetric & FDR & S-FDR & A-ERT & 4PM & COUP \\
\hline Cervinia & 2014 & $2007-$ & 2014 & - & 2013, 2014 & - \\
\hline Schilthorn & $2004,2013,2014$ & $2007-$ & 2013, 2014 & $2009-$ & $\begin{array}{l}\text { 1999, 2007, 2008, } 2009 \\
\text { 2010, 2012, 2013, } 2014\end{array}$ & 1999-2013 \\
\hline Gemmi & 2013, 2014 & 2013- & 2013, 2014 & - & 2013, 2014 & - \\
\hline
\end{tabular}

The FDR measurements are still ongoing and so are the A-ERT ones. The 4PM and S-FDR data are measured at the same time, usually between mid-July to mid-September.

$\left(\theta_{\mathrm{g}}\right)$ and the dry bulk density $\left(\rho_{\mathrm{b}}\right)$. The volumetric water content (VWC, $\theta_{\mathrm{v}}$ ) was then calculated using (Equation 1).

$$
\theta_{v}=\rho_{b} \cdot \theta_{g}
$$

Given the non-reproducibility and time consuming characteristics of this method, the obtained values were solely used to site-specifically calibrate the FDR-based sensors (see Methods Section FDR and Spatial FDR). All the samples were collected during the summer, in unfrozen conditions, to prevent the presence of ice from disturbing the results. Furthermore, the accessibility of the sites prevented us from taking more samples than once or twice a year. Thus the soil samples on their own cannot be used for the spatial and/or temporal VWC monitoring.

\section{FDR and Spatial FDR}

FDR methods are indirect measurement techniques that use electromagnetic waves to estimate the dielectric permittivity of the ground and relate it to its VWC. Electromagnetic waves are emitted at a fixed frequency along a transmission circuit and the resulting oscillation frequency is then a function of the surrounding medium and its VWC. The higher the VWC, the higher the effective dielectric permittivity, leading to a lower wave propagation velocity and thus lower frequencies are recorded (Schlaeger et al., 2005; Campbell Scientific, 2014).

Three different FDR-based monitoring sensors are considered in this study: SISOMOP (SMG, University of Karlsruhe, Germany) at Schilthorn, CS616 (Campbell Scientific, United States) at Cervinia and SMT100 (TRUEBNER GmbH, Germany) at Gemmi. The SMT100 is the new generation of SISOMOP 
sensors and uses the same measurement principle. The sensors were chosen for their robustness, relatively good accuracy, and high quality/price ratio. At Schilthorn and Cervinia, the respective sensors were installed since 2007 and both showed good performances in high mountain and permafrost conditions, hence the choice of the SMT100 (new version of the SISOMOP) for the SOMOMOUNT network.

Field experiments realized by Mittelbach et al. (2012) in agricultural fields showed that the SISOMOP and the CS616 sensors have an overall comparable accuracy $\left( \pm 0.03 \mathrm{~m}^{3} / \mathrm{m}^{3}\right)$, although their performance is seasonally dependent and each sensor type performs differently in variable settings. According to the manufacturer, the SMT100 also has an accuracy of \pm $0.03 \mathrm{~m}^{3} / \mathrm{m}^{3}$ in mineral soils using the factory calibration, which can be improved to $\pm 0.01 \mathrm{~m}^{3} / \mathrm{m}^{3}$ using a site-specific one (Truebner, 2012). Additionally, all the sensors have a temperature dependency and tend to underestimate the VWC by $\sim 0.02$ $\mathrm{m} 3 / \mathrm{m} 3$ at temperatures below $10^{\circ} \mathrm{C}$ and overestimate it by $\sim 0.05 \mathrm{~m} 3 / \mathrm{m} 3$ above $10^{\circ} \mathrm{C}$ (Mittelbach et al., 2012). It was also shown that for the CS616 at temperatures between 0 and $20^{\circ} \mathrm{C}$ the use of a temperature correction formula given by the manufacturer introduces unrealistically strong seasonal temperature effects (Mittelbach et al., 2012). Since the SISOMOP temperature dependency is of a similar magnitude than for the CS616 (Mittelbach et al., 2012), no temperature correction was applied. At temperatures below the freezing point the measured absolute VWC has to be used with caution since it lays outside of the temperature range tested by the manufacturers.

In order to standardize the measurements of the less established SISOMOP and SMT100 sensors, the same sitespecific calibration procedure was applied to both types of device. Using the calculated VWC from the soil samples (see above, $\theta_{\mathrm{V}}$ ) and the raw sensors outputs (so-called Moisture Counts (MC) for the SISOMOP and SMT100), an exponential calibration curve (Equation 2) including the upper and lower boundary conditions ( 0 and $100 \%$ VWC) was determined by laboratory measurements performed in air (for $0 \%$ limit) and directly in water (for the $100 \%$ limit). At Cervinia technical issues prevented the site-specific calibration, thus the absolute values have to be considered with care (accuracy $\pm 0.03 \mathrm{~m}^{3} / \mathrm{m}^{3}$; Campbell Scientific, 2014).

$$
\theta_{v}=j \cdot e^{(M C \cdot k)}
$$

The locations of the FDR monitoring sensors were chosen according to the following criteria: (1) close enough to the geophysical line and the boreholes to allow comparisons but to avoid interferences between the methods and (2) deep enough fine grained material to ensure that the sensors along the whole vertical profile are in good contact with the soil. There were only few locations meeting these criteria and finally the sensors are located $1 \mathrm{~m}$ away from the geophysical line at Schilthorn, $1.5 \mathrm{~m}$ away at Cervinia and $3 \mathrm{~m}$ at Gemmi.

In addition to this monitoring set-up, punctual spatial soil moisture measurements were carried out along the geophysical lines (see below) using a hand-held ML2x ThetaProbe (Delta-T Devices, England). The ThetaProbe is also a FDR-based sensor that can either be used for spatial measurements (as in this study) or be fixed installed for soil moisture monitoring. It consists of a portable logging unit that controls a sensor composed of four rods of $6 \mathrm{~cm}$ length that have to be completely inserted in the ground. A maximum of three measurements were taken in the immediate vicinity of each electrode/geophone, where the surface composition allowed it. A good contact with the soil was difficult to achieve especially at the two vegetation free field sites (Schilthorn and Cervinia), where the coarsegrained nature of the surface did not always allow the complete insertion of the rods into the ground. Thus at some locations only two or even no measurements were taken. Given the high variability of the collected values, the maximum value at each location was selected and will be used in this study. The maximum value is assumed here to represent the measure with the best soil contact and thus to be the most accurate one. However, the measurements have to be treated with caution since they were performed only at locations where at least $6 \mathrm{~cm}$ of fine grained material was available, which might not be entirely representative of the VWC distribution at the surface.

According to the manufacturer the ThetaProbe device has an accuracy of $\pm 0.05 \mathrm{~m}^{3} / \mathrm{m}^{3}$ when using the standard calibration function and $\pm 0.01 \mathrm{~m}^{3} / \mathrm{m}^{3}$ when using a site-specific calibration (Delta-T Devices, 2011). Given the heterogeneous composition of the surface along the geophysical profiles, no site-specific calibration was performed in this study.

\section{Automated Electrical Resistivity Tomography (A-ERT)}

To extend the punctual monitoring measurements to a full $2 \mathrm{D}$ section of the ground, Electrical Resistivity Tomography (ERT) measurements were used to calculate the VWC from the inverted specific resistivity tomograms. The ERT technique uses the resistivity differences of the various subsurface materials to determine its composition. It is particularly sensitive to phase changes between ice and water (e.g., Hauck and Kneisel, 2008). In ERT surveys sets of equally spaced electrodes are inserted in the ground along a profile line. Electrical current is then injected using two electrodes and the resulting potential difference is measured between two other electrodes. Varying center points and electrode spacing for each set of four electrodes (quadrupoles) yield a 2D distribution of the measured apparent resistivity. Finally, a standard tomographic inversion scheme (Res2dinv, Loke, 2006) is applied to invert the set of measured apparent resistivities to the specific resistivities of the subsurface materials. More details regarding data processing, inversion parameter and associated uncertainties are given in Hilbich et al. $(2009,2011)$ and Rosset et al. (2013).

Whereas ERT was used at all three study sites, an automatic ERT (A-ERT) system is only available at Schilthorn (Figure 2A). There a fixed ERT profile was already installed in 1999 with manual measurements in a seasonal context, and since 2009 resistivity values are measured by A-ERT yielding temporally high-resolution data along a $60 \mathrm{~m}$ long survey line (Hilbich et al., 2011). In this A-ERT set-up, an automated data filtering procedure is applied to the dataset to eliminate physically implausible values, overall high- and low-value outliers as well as temporal outliers within the data series and a standard inversion 
scheme is applied to produce specific resistivity data (Hilbich et al., 2011; Rosset et al., 2013).

In this study, ERT is used as an indirect method for nearsurface VWC values and additionally as input for the four-phase model (see Methods Section Four-Phase Model (4PM)). The latter requires the use of the entire profile, thus the inverted tomogram is used as input (see Methods Section Four-Phase Model (4PM)), whereas the former, being focused on the nearsurface, uses only the first depth level of the ERT measurements, where the monitoring FDR sensors are installed. At shallow depth the apparent resistivity can be considered as equal to the specific resistivity. Therefore, and to avoid the introduction of additional uncertainties through the inversion process, the apparent resistivity values are used in the near-surface approach described hereafter.

The approach used to calculate the VWC from the A-ERT measurement at Schilthorn is the direct application of Archie's law (Archie, 1942), which is an empirical relationship relating the pore water resistivity $\left(\rho_{\mathrm{W}}\right)$, the porosity $(\Phi)$ and the water saturation $\left(S_{\mathrm{w}}\right)$ to the resistivity $(\rho)$ (Equation 3$)$.

$$
\rho=a \rho_{w} \Phi^{-m} S_{w}^{-n}
$$

where $a, m$, and $n$ are three empirical parameters, which depend on the pore space geometry and inter-connectivity (Schön, 2004). The use of Archie's law for water content quantification is well established in soil sciences (e.g., Samouelian et al., 2005), the investigation of hill slopes (e.g., Huebner et al., 2015) and flood protection dikes (e.g., Rings and Hauck, 2009) but also in permafrost environments (Hauck, 2002).

To constrain the free parameters in Archie's law (here $\rho_{\mathrm{w}}, m$, and $n$ ), we consider the VWC measured by the FDR monitoring sensors and the apparent resistivity values at the same location throughout the time period 2007-2014. Porosity $(\phi)$ is hereby set to $53 \%$ according to in situ measurement done by Scherler (2006) and Archie's empirical parameter $a$ is set to 1, because its uncertainty can be included within the calibration of $\rho_{\mathrm{w}}$. The calibration procedure (Figure 1B) consists of 10,000 random combinations of pore water resistivity $\left(\rho_{\mathrm{w}}\right.$, ranging from 10 to $800 \Omega \mathrm{m}$ ), cementation exponent ( $m$, ranging from 1.3 to 3 ) and saturation exponent ( $n$, ranging from 1 to 8 ) that are generated and compared to the FDR values (the range of each parameter is defined according to King et al., 1988; Schön, 2004). The combination that minimizes the RMSE is selected.

\section{Model-Based Approaches Four-Phase Model (4PM)}

The so-called four-phase model, (4PM, Hauck et al., 2008, 2011) is a simple physically-based model, which combines ERT and refraction seismic tomography (RST) datasets to calculate the different phase contents (air, ice, and water) in the ground. ERT (see Methods Section Automated Electrical Resistivity Tomography (A-ERT)) and RST are often combined in permafrost research, since their complementary use allows for a clear differentiation between air and ice (RST) and ice and water (ERT) (Hauck and Kneisel, 2008).

The RST method utilizes the difference in p-wave velocity of each material to define the composition of the subsurface. In
RST surveys seismic waves are generated along a profile line and the arrival of the seismic p-waves is recorded at equally spaced geophones. From this, travel times of each source-geophone pair are calculated and are consequently inverted to yield a $2 \mathrm{D}$ distribution of $\mathrm{p}$-wave velocity using a Simultaneous Iterative Reconstruction Technique (SIRT) algorithm within the software REFLEXW (Sandmeier, 2011). For this, a synthetic initial velocity model of the ground was defined for each site and used to constrain the tomographic inversion. More details about data processing and inversion, also in a monitoring context, can e.g., be found in Hilbich (2010).

To apply the 4PM, the respective ERT and RST surveys should be conducted within a short time window to avoid uncertainties due to different surface conditions (moisture). The 4PM itself is based on three main equations: the previously cited Archie's law (Equation 3), an extension of the time-averaged approach by Timur (1968) to a 4 phase medium (Equation 4) and the assumption that the sum of all volumetric fractions of the ground is equal to one (Equation 5),

$$
\begin{gathered}
\frac{1}{v}=\frac{f_{w}}{v_{w}}+\frac{f_{r}}{v_{r}}+\frac{f_{i}}{v_{i}}+\frac{f_{a}}{v_{a}} \\
f_{w}+f_{r}+f_{i}+f_{a}=1 \text { with } 0 \leq f_{w}, f_{r}, f_{i}, f_{a} \leq 1
\end{gathered}
$$

where $\mathrm{v}$ is the measured p-wave velocity, $f_{w}, f_{r}, f_{i}$ and $f_{a}$ are the water, rock, ice, and air fractions and $v_{w}, v_{r}, v_{i}$, and $v_{a}$ their respective p-wave velocities (Hauck et al., 2011). Combining Equations (3-5), $f_{w}, f_{i}$, and $f_{a}$ can be calculated as a function of the material properties $\rho_{w}, v_{r}, v_{w}, v_{a}, v_{i}$ and the three Archie parameters $(a, m$, and $n)$ under the constraint that a porosity model $\left(1-f_{r}\right)$ has to be prescribed.

Among these parameters the pore water resistivity $\left(\rho_{\mathrm{W}}\right)$ and the porosity $(\Phi)$ are the most sensitive ones for the ice and water content calculation (Hauck et al., 2011). The difficulty of in situ measurements and its spatial variability make the porosity particularly challenging to include in the 4PM. Several approaches have been tested so far to optimize its determination. Hauck et al. (2011) proposed to use a general version of the 4PM, where the calculations are done for the whole range of plausible porosity values, which yields the range of possible volumetric fractions. Additionally, the use of one single value for the whole $2 \mathrm{D}$ section (homogeneous porosity) was tested as well as the use of a gradient porosity model following the assumption that porosity decreases with depth.

In addition to the importance of a correctly estimated porosity model for the accuracy of the 4PM, inadequate porosity values are also one of the main causes for physically inconsistent solutions in the 4PM. The two main error sources for such inconsistent solutions are: (1) a negative phase content or a modeled porosity larger than one (violation of Equation 5) and (2) phase content values exceeding the prescribed porosity (Hauck et al., 2011). These errors typically appear at the lower boundary of the model, where the porosity is lowest (and the sensitivity of the geophysical inversion results is the smallest) and in sections of anomalously high resistivity (Hauck et al., 2011). They are 
permitted by the fact that Archie's law and Timur's equation are not bounded to physically realistic solutions and allow tradeoffs between the different phase contents. All the solutions that violate the restriction of Equation 5 are deleted in the final model, producing white grid cells. In a perfect case, the final phase content distribution should have the same shape and extent as the input ERT and RST data. This can be achieved using a coherent combination of parameters (specifically porosity) and appropriate inversion scheme that prevent the generation of artifacts in the input ERT and RST profiles.

In this study we developed a new approach to better prescribe the porosity in the $4 \mathrm{PM}$, which combines modeled porosity in the near surface and a user defined gradient at depth. We use the fact that in unfrozen conditions $\left(f_{i}=0\right)$ the number of unknowns in the $4 \mathrm{PM}$ is reduced to three (water content, air content, rock content $=1$-porosity), which enables the porosity to be modeled explicitly. This is defined as a three-phase model or 3PM hereafter. Since ERT and RST measurements were realized during late summer, the uppermost soil layer of the profiles was unfrozen (the so-called active layer), which allows us to calculate spatial porosity variations for this zone using the 3PM. The 3PMderived porosity model is then used as input in the 4PM, and the depth to the frozen layer is defined as the depth where $f_{i} \neq 0$ or where no solution is found in the 4PM (due to violation of Equation 5, see above). At this interface between unfrozen and frozen conditions, a user-defined gradient is applied to further decrease the porosity until the assumed minimum porosity (firm bedrock) is reached.

For this gradient model at larger depths, two types of gradients can be used. On the one hand, a laterally homogenous decreasing porosity gradient can be prescribed, which is entirely user-defined (starting porosity value, gradient and minimum value) and totally independent from the modeled 3PM porosity above (so-called 3PM-independent gradient). On the other hand, a laterally variable decreasing porosity gradient can be set, which uses the lowermost available value from the 3PM-derived porosity (at the boundary to the frozen layer) for each soil column as starting value (so-called 3PM-dependent gradient). For this, only the gradient and the minimum porosity value (bedrock) are user-defined. A smoothing scheme is applied on the resulting porosity models to avoid unrealistic vertical structures and too high porosity contrasts. The 3PM-dependent gradient is used when the porosity distribution at the surface is assumed to be representative for larger depths, whereas the 3PM-independent gradient is used when the porosity variations obtained at the surface are assumed to be superficial structures.

\section{Four-phase model calibration}

Besides the porosity, also a number of other parameters have to be prescribed in the 4PM: $\rho_{w}, m, n, v_{w}, v_{r}, v_{i}$, and $v_{a}$. The seismic velocities of water $\left(v_{w}\right)$, ice $\left(v_{i}\right)$ and air $\left(v_{a}\right)$ are set to standard values from literature: $v_{w}=1500 \mathrm{~m} / \mathrm{s}, v_{i}=3500 \mathrm{~m} / \mathrm{s}$ and $v_{a}=300 \mathrm{~m} / \mathrm{s}$, whereas the p-wave velocity of the rock $\left(v_{r}\right)$ is site-specific and depends on the rock type. The theoretical p-wave velocity found in non-fractured bedrock is considered in the model. It can vary from $5000 \mathrm{~m} / \mathrm{s}$ for sandstones up to $8500 \mathrm{~m} / \mathrm{s}$ in peridotites, with a value around $6000 \mathrm{~m} / \mathrm{s}$ for limestones (Schön, 2004).

The availability of spatially distributed soil moisture values along the geophysical profiles at all three study sites allows us to calibrate the Archie parameters $\Phi, \rho_{\mathrm{W}}, m$ and $n$ using the measured spatial soil moisture values (S-FDR, see Methods Section Automated Electrical Resistivity Tomography (A-ERT)). The calibrated parameters are the same as for the A-ERT approach in Methods Section Automated Electrical Resistivity Tomography (A-ERT), but the procedure is different (Figure 1C). Instead of prescribing the porosity, we here explicitly calculate the porosity close to the surface using the 3PM (as described above). For this, 10,000 random combinations of $m$ (ranging from 1.3 to 3 ), $n$ (ranging from 1 to 8 ) and $\rho_{\mathrm{w}}$ (ranging from 10 to $800 \Omega \mathrm{m}$ ) are used to model $\Phi$ (under the assumption of ice-free conditions) and the VWC at the surface (the ranges of these parameters were defined according to King et al., 1988; Schön, 2004). The measured VWC (S-FDR) is then compared to each of the $3 \mathrm{PM}$-derived VWC modeled using the 10,000 combinations of $m, n$, and $\rho_{\mathrm{w}}$. The set of parameters with the lowest RMSE is selected for the further application of the 3PM and 4PM.

The accuracy of this automatic calibration procedure depends both on the quality of the S-FDR data and on the presence or absence of inversion artifacts in the geophysical tomograms. Regarding the S-FDR sensors accuracy, they have an overall accuracy of $\pm 0.05 \mathrm{~m}^{3} / \mathrm{m}^{3}$ (see Methods Section FDR and Spatial FDR). Furthermore, the average standard deviation between the measurements at the same location is $0.028 \mathrm{~m}^{3} / \mathrm{m}^{3}$ at Schilthorn, $0.034 \mathrm{~m}^{3} / \mathrm{m}^{3}$ at Cervinia and $0.091 \mathrm{~m}^{3} / \mathrm{m}^{3}$ at Gemmi.

\section{CouP Model}

The COUP model is a 1-dimensional physically-based model used for the simulation of different thermal and hydrological processes (Jansson and Karlberg, 2004). It couples heat and water processes in the subsurface using the general heat flow equation (Equation 6) and is extended with empirical relations for the calculation of many thermal and hydrological soil variables. It also includes snow cover, freeze/thaw processes and vegetation if present. The general heat flow equation is formulated as follow (Jansson and Karlberg, 2004):

$$
\frac{\delta(C T)}{\delta t}-L_{f} \rho_{d} \frac{\delta \Theta_{i}}{\delta t}=\frac{\delta}{\delta z}\left(k \frac{\delta T}{d z}\right)-C_{w} T \frac{\delta q_{w}}{\delta z}-L_{v} \frac{\delta q_{v}}{\delta z}
$$

where $C\left(\mathrm{~J} \mathrm{~K}^{-1}\right)$ is the heat capacity of the soil, $\mathrm{T}(\mathrm{K})$ is the soil temperature, $\mathrm{L}_{\mathrm{f}}\left(\mathrm{J} \mathrm{kg}^{-1}\right)$ is the latent heat of freezing, $\rho_{\mathrm{d}}\left(\mathrm{kg} \mathrm{m}^{-3}\right)$ is the density, $\theta_{\mathrm{i}}$ is the volumetric ice content, $\mathrm{k}\left(\mathrm{W} \mathrm{m} \mathrm{m}^{-1} \mathrm{~K}^{-1}\right)$ is the thermal conductivity, $\mathrm{t}$ is the time, $\mathrm{z}$ is the depth, $\mathrm{C}_{w}\left(\mathrm{~J} \mathrm{~K}^{-1}\right)$ is the heat capacity of the water, $\mathrm{L}_{\mathrm{v}}\left(\mathrm{J} \mathrm{kg}^{-1}\right)$ is the latent heat of vaporization and $\mathrm{q}_{w}$ and $\mathrm{q}_{v}\left(\mathrm{~kg} \mathrm{~m}^{-2} \mathrm{~s}^{-1}\right)$ are the water and vapor fluxes. The upper thermal boundary condition is calculated by a complete energy balance at the soil surface and the lower thermal boundary condition is derived from the sine variation of the temperature at the soil surface and a damping factor for the depth. 
The water flow in the soil is assumed to be laminar, following Darcy's law as generalized by Richards (1931) for unsaturated soils (Equation 7).

$$
q_{w}=-k_{w}\left(\frac{\delta \psi}{\delta z}-1\right)-D_{v}\left(\frac{\delta c_{v}}{\delta z}\right)+q_{\text {bypass }}
$$

where $\mathrm{k}_{\mathrm{W}}$ is the unsaturated hydraulic conductivity ( $\mathrm{mm} /$ day), $\Psi$ is the water tension $\left(\mathrm{N} \mathrm{m}^{-1}\right), \mathrm{C}_{v}$ is the concentration of vapor in soil air, $\mathrm{D}_{\mathrm{v}}$ is the diffusion coefficient for vapor in the soil and $q_{\text {bypass }}$ is a bypass flow in the macro-pores. Under supersaturated conditions, the flow of water is accumulated upwards in the upper soil compartment until it reaches the surface and leaves the system with the surface runoff. The modeled processes of water infiltration into the frozen soil were implemented and described by Stähli et al. (1996) and a complete description and test of water infiltration is given by Scherler et al. (2010).

The model has already been used in many studies focussing on various purposes, including soil moisture (e.g., Noroozvalashedi et al., 2012; Wu and Jansson, 2013) and permafrost (Engelhardt et al., 2010; Marmy et al., 2013, 2015; Scherler et al., 2013, 2014; Staub et al., 2015). Other studies specifically applied the COUP model to simulate the soil moisture in frozen grounds (Scherler et al., 2010; Xarpell et al., 2010; Python, 2015). The model has already shown good ability to simulate ground temperature regimes, precise snow conditions and soil moisture. However limitations exist regarding 2- or 3-dimensional processes, such as energy transfer by subsurface convection in blocky surface layers (Scherler et al., 2014) or 2D air circulation in ventilated talus slopes (Staub et al., 2015).

Here we use the COUP model as calibrated by Marmy et al. (2015). In their study the COUP model was used at several high elevation study areas for the assessment of future long-term ground temperature evolution. Therefore, a semi-automated calibration procedure was used (see Marmy et al., 2015) and the COUP model was driven by on-site reconstructed meteorological data (air temperature, relative humidity, wind speed, global radiation, and precipitation) at daily resolution (see Rajczak et al., 2015) for the period 1999-2013 with a 18 year spin-up (19811999). The complete energy and mass balance are calculated along a soil column composed of 16 compartments of increasing thickness with depth, from which the water and ice content can be extracted.

\section{FIELD SITES AND DATASETS}

This methodology was applied to three well established permafrost study areas in the western European Alps: Schilthorn, Cervinia, and Gemmi (see Figure 2). The sites were chosen based on data availability and their differing subsurface properties to test the accuracy of the presented methods in various conditions.

\section{Schilthorn}

The Schilthorn study area (see Figure $\mathbf{2 A}$ ) is located in the northern Swiss Alps at $2900 \mathrm{~m}$ a.s.l. on a small plateau in the north facing slope of the Schilthorn summit $(2970 \mathrm{~m}$ a.s.l.). The mean annual air temperature is around $-3^{\circ} \mathrm{C}$
(PERMOS, unpubl.) and the average precipitation around $2700 \mathrm{~mm}$ per year (Imhof et al., 2000). The subsurface is composed of micaceous shales with interbedded ferruginous quartzose sandstones underlying a thin layer of weathered material (Imhof et al., 2000). This particular geology is the source of quite different (i.e., more conductive) electrical properties than observed at other alpine permafrost sites (Vonder Mühll et al., 2000). The surface cover consists of a layer of fine grained debris including sandy and silty materials up to several meters thick (Hilbich et al., 2008) without any vegetation (see Figure 2A).

Permafrost was first discovered in the Schilthorn massif during the construction of the cable car station in 1965. Since then, the site has been extensively studied and became one of the most important study area of the Swiss permafrost monitoring network PERMOS (2013). The measurements comprise: ground temperature monitoring in three boreholes ( $14 \mathrm{~m}$ and two times $100 \mathrm{~m}$ ) drilled and instrumented in 1998 and 2000 within the project PACE (Harris et al., 2001), a meteorological station installed in 1999, two fixed ERT profiles (50 electrodes with $2 \mathrm{~m}$ spacing and 47 electrodes with $4 \mathrm{~m}$ spacing) installed in 1999 and 2005, respectively, which were automatized (A-ERT) in 2009 (Hauck, 2002; Hilbich et al., 2008, 2011) and annual RST measurements performed since 2007 (Hilbich, 2010) along one of the ERT monitoring lines. Continuous soil moisture measurements have been running since 2007, soil samples were collected in 2004, 2013, and 2014 and spatial FDR measurements were performed in late summer 2013 and 2014 (see Table 1 for a summary).

From the borehole data it is known that permafrost at Schilthorn is at least $100 \mathrm{~m}$ thick and characterized by temperatures close to the freezing point and ice-poor conditions. The active layer thickness (ALT) typically varies between 4 and $6 \mathrm{~m}$ with maximum of $8.55 \mathrm{~m}$ in 2003 (PERMOS, 2013). The possible long term evolution of permafrost at Schilthorn was investigated using the COUP model and downscaled RCM scenarios for the next 100 years (Marmy et al., 2013, 2015; Scherler et al., 2013). According to these studies, permafrost at Schilthorn is comparatively sensitive and will probably start to degrade early within this century.

\section{Cime Bianche/Cervinia}

The Cime Bianche monitoring site is located above Cervinia at $3100 \mathrm{~m}$ a.s.l. in the Italian Alps close to the border to Switzerland. The station is situated on a plateau slightly westoriented and the subsurface is mainly composed of granetiferous mica schists and calcschists (Figure 2B). The bedrock surface is highly weathered resulting in a layer of coarse-debris ranging from a few centimeters to several meters depth. The surface aspect is locally very heterogeneous with an alternation of visible bedrock outcrops, coarse-grained material, and fine-grained material (Pogliotti et al., 2015). As for Schilthorn, no vegetation is present at the site (see Figure 2B). In situ records for the 20102013 period show a mean annual precipitation of $1200 \mathrm{~mm}$ and a mean annual air temperature of $-3.2^{\circ} \mathrm{C}$ (Pogliotti et al., 2015).

Permafrost was first identified in the area in 1990 with BTS measurements and geoelectrical soundings (Guglielmin and Vanuzzo, 1995). The instrumentation of the site started in 2005 
and was progressively developed until 2008 (Pogliotti et al., 2015). Measurements at the site include: ground temperature monitoring in two boreholes (41 and $7 \mathrm{~m}$ depth) drilled in 2004, a spatial grid of ground surface temperature logger measuring since 2006 and an automatic weather station also installed in 2006. Geophysical (ERT and RST) investigation took place in the vicinity of the boreholes in October 2013 and were repeated in September 2014. Continuous soil moisture measurements at $20 \mathrm{~cm}$ depth are running since 2007, soil samples were collected in 2014 and measurements with the hand held FDR probe were conducted along the geophysical survey lines.

The permafrost at Cime Bianche is characterized by a temperature of around $-1.2^{\circ} \mathrm{C}$ and the active layer thickness varies between 1.9 and $3.6 \mathrm{~m}$ at the shallow borehole and between 3.8 and $5.4 \mathrm{~m}$ at the deep one. These strong spatial differences are most likely due to difference in ice content between the two boreholes (Pogliotti et al., 2015).

\section{Gemmi}

The Gemmi monitoring site (see Figure 2C) is situated at $2450 \mathrm{~m}$ a.s.l. in the Furggentälti valley located in the main alpine ridge in Switzerland. This west-oriented high alpine valley receives between 1800 and $2500 \mathrm{~mm}$ precipitation per year and has a mean annual air temperature around $0^{\circ} \mathrm{C}$ (Krummenacher et al., 2008). The geology of the study area is mainly composed of limestones from the kimeridigian period and many karstic formations can be observed throughout the area. Typically, no surface water flow is observed in the Furggentälti valley, since all the water is drained by the multiple fissure and cave systems inherent to the karstic environment. The near-surface is composed of a fine-grained material layer underlying a thin organic layer ( $\sim 10 \mathrm{~cm}$ thick at the SOMOMOUNT station) and grass growing at the surface (see Figure 2A). The thickness of this succession of layer varies between a few centimeters up to several meters. Locally some bedrock outcrops are visible.

The site was first investigated for its geomorphologic interest and instrumentation started in 1988 for quantitative measurements of periglacial processes. Two main geomorphic features are currently investigated: an active rock glacier and a solifluction lobe. Measurements in the Furggentälti valley are focused on the dynamic of these two landforms and comprise repeated GPS campaigns on the rock glacier, an automatic

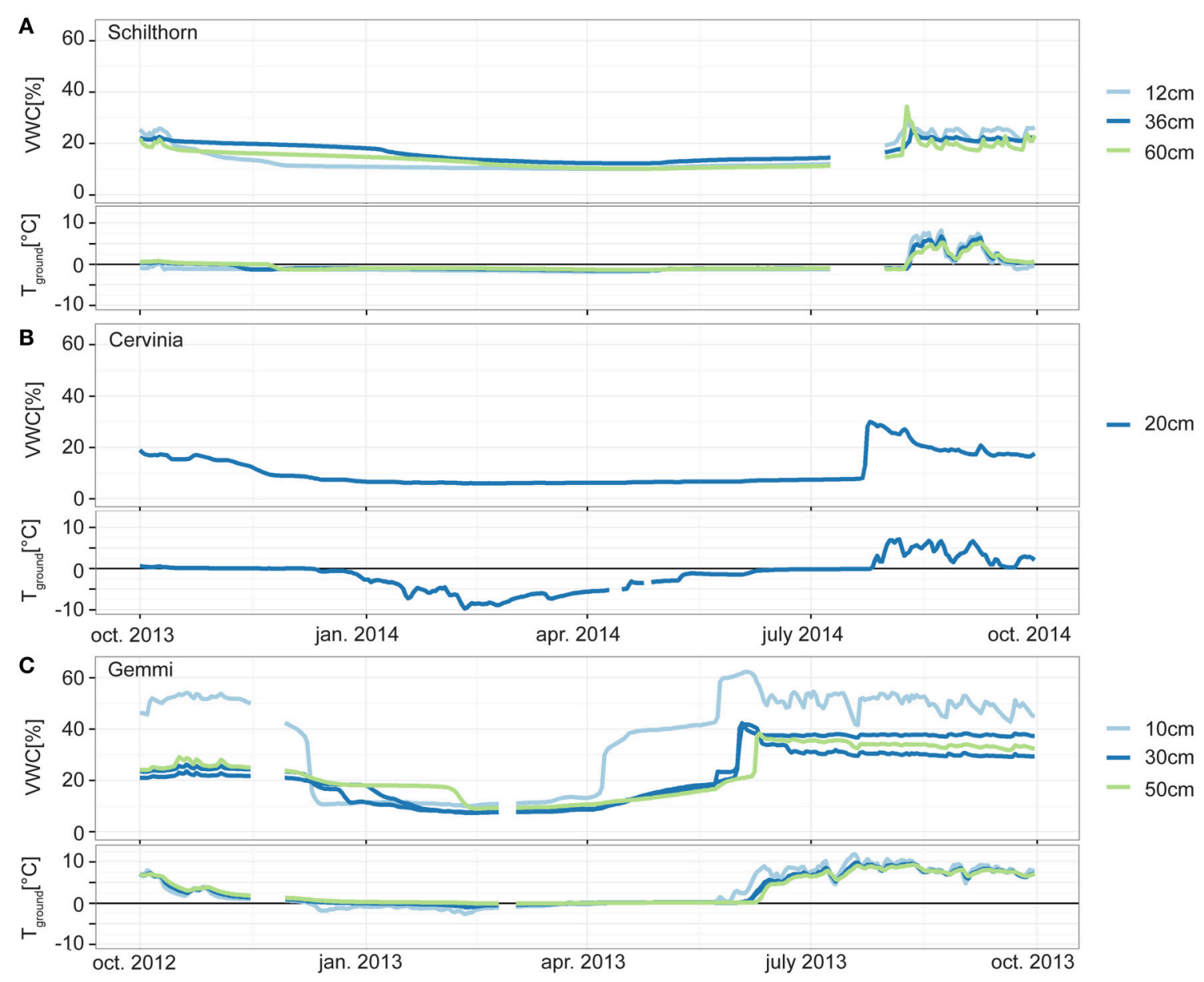

FIGURE 3 | Temporal evolution of the measured soil moisture (upper panel) and ground temperature (lower panel) at (A) Schilthorn, (B) Cervinia, and (C) Gemmi for the year 2013 (A,B) and 2014 (C). Missing data prevented the use of the same time period for each site and the gaps were too large to apply gap-filling techniques. 
camera installed in 1993 for the rock glacier monitoring and the application of photogrammetric analyses since 1990. Additionally a vertical temperature profile measuring down to $1 \mathrm{~m}$ depth was already installed in 1988 on the solifluction lobe (Krummenacher and Budmiger, 1992). Two weather stations were installed in 1999 and 2000 on the solifluction lobe and on the rock glacier, respectively. In 2013, with the start of the SOMOMOUNT project, a soil moisture monitoring station was installed on the solifluction lobe, several geophysical surveys (ERT and RST) were performed in the vicinity accompanied by spatial FDR and different soil samples (see Table 1).

The vertical temperature profile of the uppermost meter of the solifluction lobe reveals the probable absence of permafrost at this site, but shows strong seasonal frost effects. This study area is included here precisely for that reason as it permits to assess the accuracy of the $4 \mathrm{PM}$ in unfrozen conditions as well as the application of the 3PM.

\section{RESULTS}

\section{Soil Moisture Monitoring}

Figure 3 shows the results of continuous monitoring of VWC with the FDR sensors at Schilthorn, Cervinia, and Gemmi. At all sites, the overall annual behavior of VWC is similar and characterized by a steady minimum throughout the winter followed by a strong increase at every depth at the beginning of the summer (around mid-April at Gemmi and beginning of

TABLE 2 | Summary of the parameters selected for Archie's law at Schilthorn and the 4PM ones at each sites.

\begin{tabular}{lccccc}
\hline Parameters & \multicolumn{2}{c}{ Archie } & & \multicolumn{3}{c}{ 4PM } \\
\cline { 2 - 3 } \cline { 5 - 6 } & Schilthorn & & Schilthorn & Cervinia & Gemmi \\
\hline $\mathrm{m}$ & 1.72 & & 1.4 & 3 & 2.8 \\
$\mathrm{n}$ & 1.63 & & 2.4 & 2.4 & 7.4 \\
$\rho_{\mathrm{W}}[\Omega \mathrm{m}]$ & 55 & & 60 & 60 & 55 \\
$\mathrm{~V}_{\mathrm{r}}\left[\mathrm{ms}^{-1}\right]$ & - & & 6000 & 7000 & 7000 \\
$\Phi_{\min }[\%]$ & - & & 10 & 10 & 10 \\
$\mathrm{RMSE}[\%]$ & 2.2 & & 4.65 & 7.07 & 30.5 \\
\hline
\end{tabular}

The application of Archie's law at Schilthorn is restricted to the near-surface, thus the porosity measured by Scherler (2006) is used.
August at Schilthorn) and a period of high variability due to precipitation events between mid-July and mid-October. Around mid-October (mid-November at Gemmi) the VWC decreases (more or less rapidly depending on the site and depth considered) to reach the winter minimum again. This winter minimum is $6 \%$ at $20 \mathrm{~cm}$ depth at Cervinia, $9-11.5 \%$ at Schilthorn, and $7.5-11 \%$ at Gemmi (depending on the depth considered).

The VWC evolution described here is mainly driven by the ground temperature and the in situ snow cover, which is typical for high-altitude permafrost sites (e.g., Hilbich et al., 2011). The winter minimum corresponds to the frozen state of the ground and the insulating snow cover prohibits any heat exchange between the atmosphere and the ground. At all sites the maximum value is reached shortly after snow melt, as long as the ground is still frozen and sealed by ice, which prevents infiltration and causes saturated conditions in the layer above. These maximum values are thought to be representative for saturated conditions and thus porosity of the near surface. Finally, the highly variable period in summer corresponds to a snow-free and unfrozen state that allows a coupling between precipitation events and soil moisture to take place.

Although, the overall VWC evolution is similar at all sites, some important differences have been observed and will be discussed more in detail in Section Discussion. At Schilthorn, the peak in the beginning of the summer is immediately followed by a strong decrease of the VWC, whereas the VWC at Cervinia slowly and steadily decreases throughout the whole summer. Furthermore, soil moisture in 2014 at Gemmi is much higher than at the two other sites and the three measurement depths exhibit larger variability than at Schilthorn. Additionally, the duration of the winter minimum state is shortest at Gemmi (the non-permafrost site) and the periods related to the zero curtain effect (effect of latent heat in maintaining near $0^{\circ} \mathrm{C}$ temperature over extended periods in freezing or thawing soils Outcalt et al., 1990) at the beginning and the end of the summer are much longer than at the other sites.

\section{A-ERT}

Among the field sites of this study only the Schilthorn is equipped with A-ERT, resistivity monitoring data with high temporal resolution are therefore only available for this site. Using the soil moisture monitoring data for calibration, the
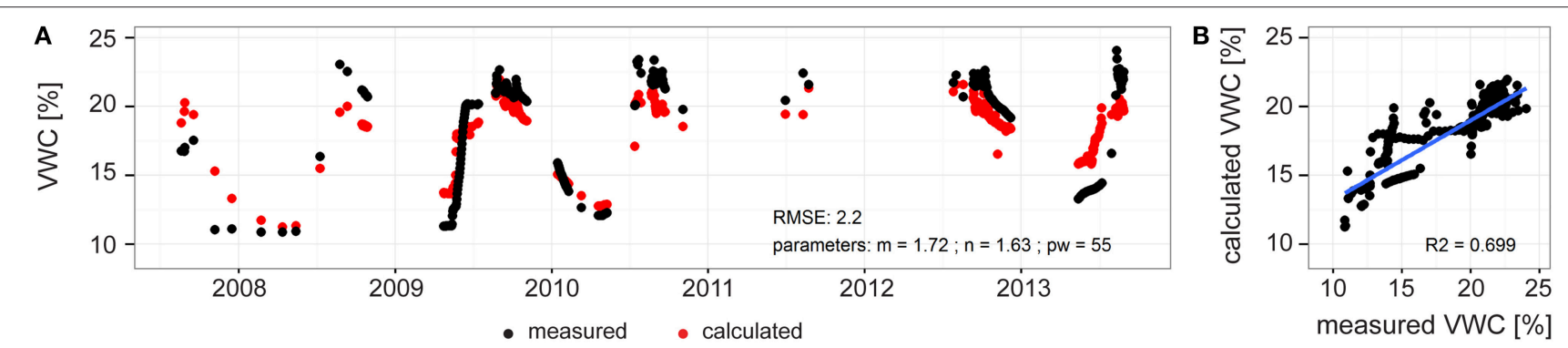

FIGURE 4 | Calibration of the A-ERT-derived VWC using Archie's law (red) compared to the measured VWC (black) at Schilthorn (A), and the performance of the calibration (B). The blue line represents the linear regression between calculated (Archie) and measured (FDR) data. 
near-surface spatio-temporal VWC was calculated from the apparent resistivity values (see Methods Section Automated Electrical Resistivity Tomography (A-ERT)). In a first step, Archie's law was calibrated at the location of the FDR monitoring sensors. The resulting parameter values are listed in Table 2 and Figure 4 shows the AERT-derived VWC (red) compared to the measured VWC (black) over the period 2007-2014 (A) and the performance of the method (B).

This calibration shows a good overall agreement with a systematic underestimation for the summer periods and overestimation during the winter. The offset between measured (FDR) and calculated (Archie's law) VWC is not constant but varies between -5.6 and $5.3 \%$ depending on the season and the year considered. The transition periods also correspond well.

In a second step the calibrated Archie's formula was applied to the uppermost data level along the entire ERT profile to get the spatial distribution of near-surface VWC with time. Figure 5A shows the spatio-temporal evolution of calculated VWC (Archie's law) at the surface from May to November 2009. Figure 5B compares the temporal evolution of measured (FDR) and calculated (Archie) values at the location of the two boreholes SCH_5198 and SCH_5000.

One can clearly see a non-uniform spatial repartition of VWC along the profile line. Dry conditions with a low temporal variability can be found between 24 and $48 \mathrm{~m}$ (zone a in Figure 5A) and the wettest conditions with higher overall amplitudes are recorded between 10 and $24 \mathrm{~m}$ (zone b). This is in good agreement with previous observations made by Hilbich et al. (2008) and Hauck (2001).

A marked increase in VWC can be observed at the beginning of the summer. Within a very short time period (a few days) all values along the survey line increase by about $5 \%$ even though the surface material is quite heterogeneous and spatially variable snow melt and runoff conditions can be observed. This event is also recorded in the measured FDR data, where it lasts longer but has a bigger amplitude. A second marked peak was measured in mid-July by the FDR. Generally, the A-ERT-derived VWC is temporally much less variable than the values of the direct FDR measurements as the resistivity values integrate over larger depths $(\sim 50 \mathrm{~cm})$.

\section{Four-Phase Model}

Based on the ERT and RST profiles of all three sites, the porosity was modeled following the 3PM-4PM scheme described in Methods Section Four-Phase Model (4PM) (3PMdependent, Figure 6). The spatial variation of the porosity at the surface (lower panels in Figure 6) seems consistent with field observations at all sites. However, the absolute values at the surface are clearly overestimated. At Schilthorn, previous porosity measurements near the borehole SCH_5198 found values of around $53 \%$ at $10 \mathrm{~cm}$ depth (Scherler, 2006), whereas the 3PM-4PM scheme models $67 \%$. However, the spatial distribution of porosity is in accordance with the observed surface characteristics: the uppermost ground layer is composed of weathered material of variable granulometry and depth. At Cervinia, the same observation can be made. The porosity modeled at the surface shows unrealistic values of up to $85 \%$, but the spatial porosity distribution is consistent with the observed coarse grained material along most parts of the profile and the bedrock outcrop around the location of the borehole DP. Finally, at Gemmi the 4PM-defined porosity is nearly reaching $100 \%$ at the surface in the left part of the profile, which is again a clear overestimation. However, the highest values are found at the location of the solifluction lobe (Krummenacher et al., 2008) and the lowest values (50-60\%) are found between 40 and $70 \mathrm{~m}$ horizontal distance, which coincides with bedrock outcrops visible in this part (see also Figure 8D).

Given the good spatial distribution but the strongly overestimated porosity values, we modified the porosity models determined by the $3 \mathrm{PM}-4 \mathrm{PM}$ scheme in order to create so-called

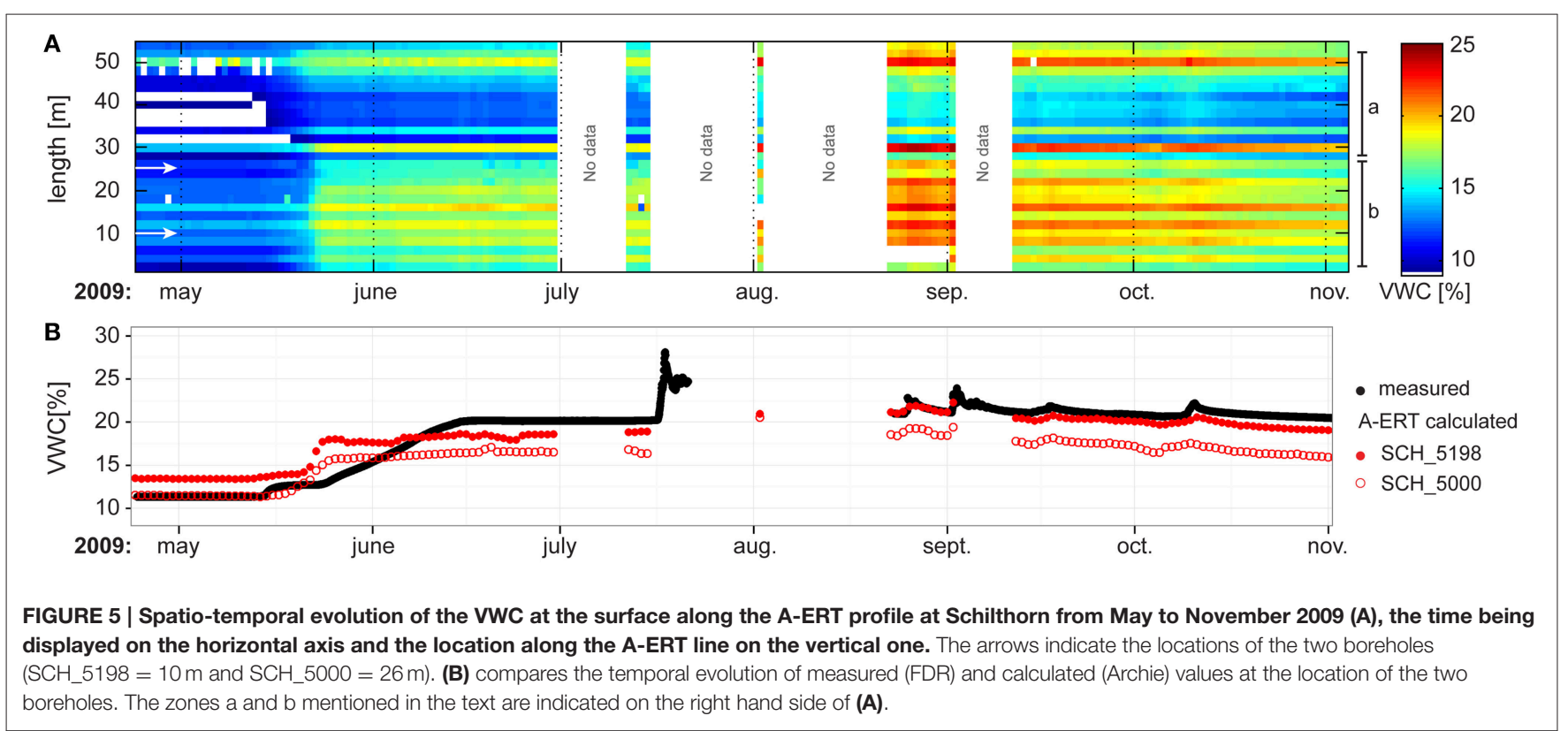




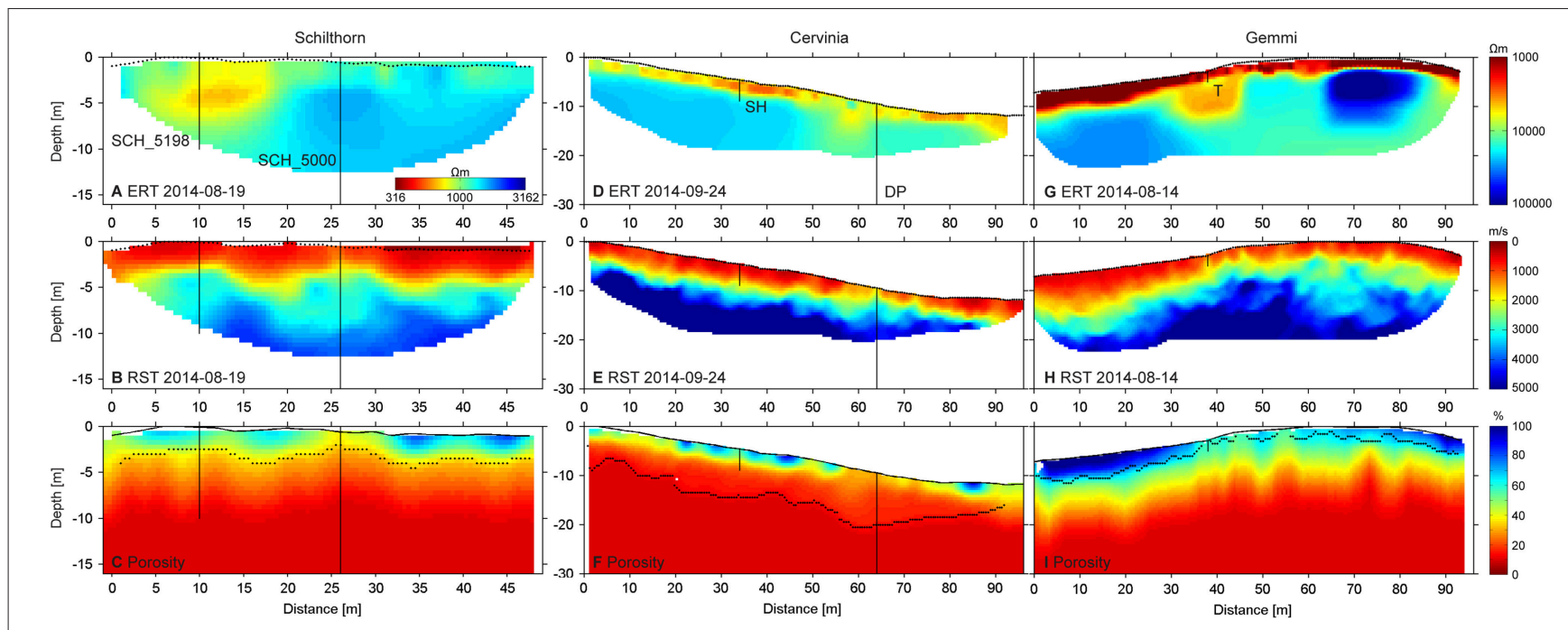

FIGURE 6 | Inverted specific resistivities (A,D,G) and p-wave velocities (B,E,H) for Schilthorn, Cervinia, and Gemmi. Note the different resistivity color scale at Schilthorn. The porosity models (C,F,I) are computed using a 3PM-dependent gradient [see Methods Section Four-phase model (4PM)]. Black lines indicate borehole positions, and dotted lines indicate the maximum depth of the 3PM-derived porosity.
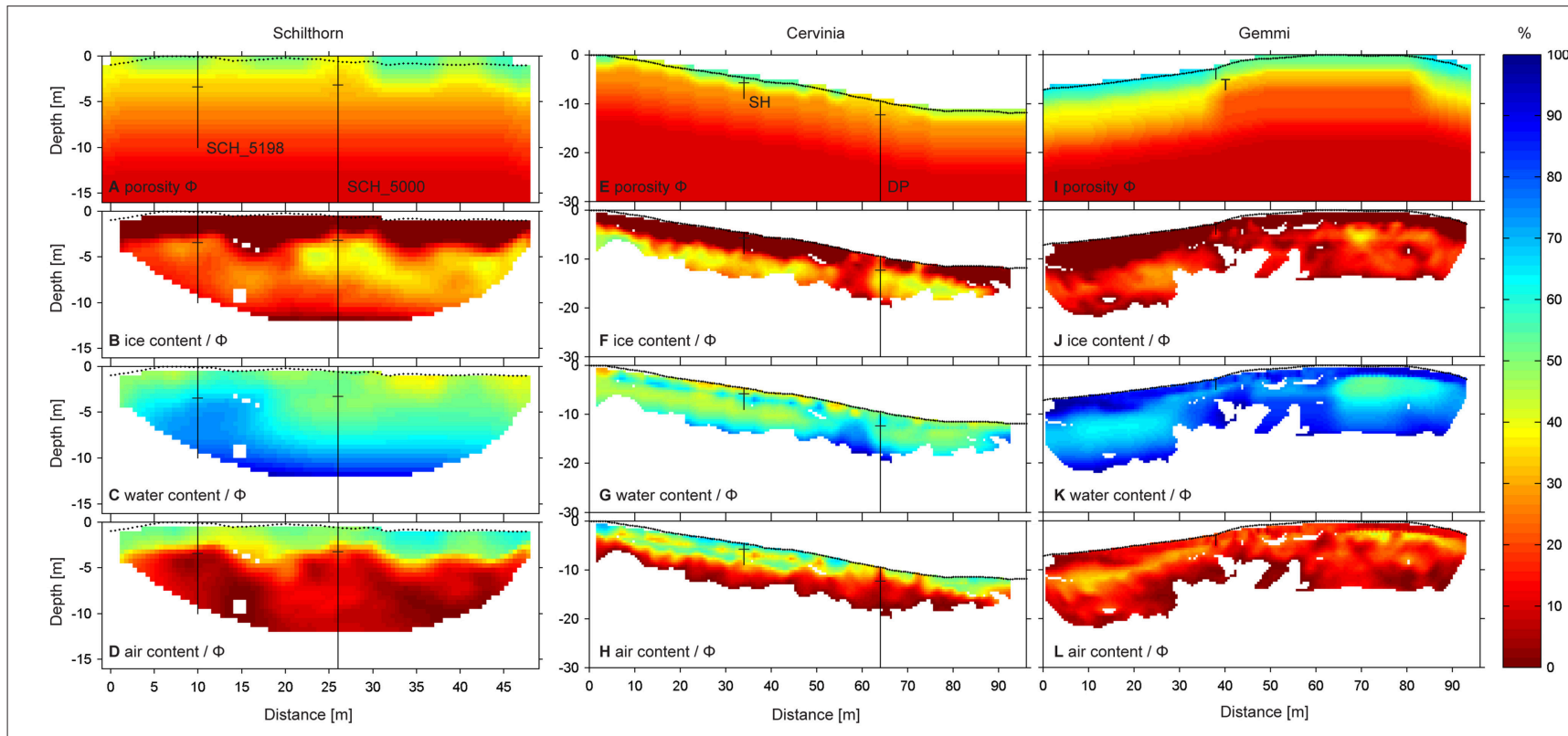

FIGURE 7 | 4PM modeled relative ice- (B,F,J), water- (C,G,K), and air- (D,H,L) contents at Schilthorn, Cervinia, and Gemmi using best guess porosity models (A,E,I). The borehole locations and temperature profiles are marked by vertical black lines and the measured ALT at the boreholes by horizontal ones.

best-guess porosity models for all sites, which add information from absolute values derived from field observations, drilling logs and expert's knowledge to the model yielded by the 3PM4PM scheme. In the following these manually adapted best-guess porosity models are used to constrain the 4PM with more realistic values. Figure 7 shows the best-guess porosity models and the 4PM-modeled ice, water and air content at Schilthorn, Cervinia, and Gemmi. Each panel represents a 2D section of the ground and the values of the different phase contents are given relative to the available pore spaces (in percent per porosity, except for the porosity itself).

Looking at the ice content distribution (Figures 7B,F,J), one can observe an unfrozen layer $\left(f_{i}=0\right)$ near the surface at all three sites. At Schilthorn and Cervinia the thickness of this icefree layer is coherent with the observed active layer. At Gemmi, no evidences of permafrost have been found so far, so that the presence of ice in our results is considered as an artifact (see Section Discussion for more details). At Schilthorn and Cervinia 
the depth of the active layer is variable along the profile line and between the two sites, which agrees well with the temperatures recorded in the boreholes.

Clear differences between the two sites can be observed in the relative values of ice content (i.e., the percentage of pore spaces filled with ice). Maximum values at Schilthorn are around 40\%, whereas the ice content can reach up to $50 \%$ of the available pore spaces at Cervinia. Furthermore, most of the profile at Schilthorn has a value of around 25\%, whereas at Cervinia several ice-rich zones (up to 55\%) are alternating with ice-poor ones (around 15\%). Again, this is in good agreement with the borehole temperatures, showing around $-0.5^{\circ} \mathrm{C}$ for the permafrost body at Schilthorn and with $-1.25^{\circ} \mathrm{C}$ colder conditions at Cervinia. This temperature difference can explain the higher ice content modeled at Cervinia and the higher VWC seen at Schilthorn. Additionally, the resistivities observed at Schilthorn are much lower ( $\max \sim 2500 \Omega \mathrm{m}$, Figure 6A) than at Cervinia ( $\max$ $\sim 25000 \Omega \mathrm{m}$, Figure 6D) indicating less fractured bedrock and/or higher ice content at Cervinia.

The VWC distributions (Figures 7C,G,K) show high variability at the surface and an increase with depth at all sites. The relative values at Schilthorn and Cervinia are somewhat similar (35-55\%) and much higher at Gemmi (45-100\%, i.e., full saturation). This is coherent with the respective site locations and substrate. At Gemmi low water content areas can be seen on the right and left side of the profile starting at $5 \mathrm{~m}$ depth, which correspond to high porosity and high air content areas.

Finally, looking at the air content distribution (Figures 7D,H,L), a typical decrease with depth is seen at Schilthorn and Cervinia, which is a function of the modeled porosity. Interestingly at Gemmi, the distribution follows a completely different pattern. High air content zones are found around $5 \mathrm{~m}$ depth on the left- and right-hand sides of the profile. This distribution corresponds to the high resistive anomalies found in the ERT (Figure 6G) and is coherent with the karstic composition of the subsurface and the probable presence of cavities or cracks in the bedrock.

\section{DISCUSSION}

\section{Soil Moisture Monitoring}

The continuous monitoring of soil moisture at three high alpine field sites allowed us to identify variable, site-dependent patterns of VWC temporal evolution. At Schilthorn, the strong increase in VWC at the beginning of the summer is followed by a fast decrease indicating most probably an effective drainage of the water. This hypothesis is supported by the site location on a small plateau within a steep slope and the composition of the uppermost meters of the ground (Imhof et al., 2000). Additionally, the thick active layer observed in the boreholes (4.7-7.7 $\mathrm{m}$ for the period 2007-2014; PERMOS, 2013) allows water to infiltrate deep in the ground before reaching the impermeable permafrost body, thus draining efficiently the nearsurface.

At Cime Bianche/Cervinia the snow cover thickness and duration as well as the surface characteristics are very similar to
Schilthorn, but the VWC evolution is different. Here, the peak at the beginning of the summer is followed by a slow and steady decrease of VWC over the whole summer period. As the field site on Cime Bianche is located on an only slightly inclined mountain plateau, we interpret this difference to Schilthorn as being a consequence of topographic conditions, which facilitate the storage of snow melt water. Furthermore, the permafrost at Cime Bianche is colder than at Schilthorn $\left(-1.25^{\circ} \mathrm{C}\right.$ at Cime Bianche in contrast to $-0.5^{\circ} \mathrm{C}$ at Schilthorn at the depth of zero annual amplitude, respectively) and the active layer is shallower (1.9$3.6 \mathrm{~m}$ for the period 2007-2013, Pogliotti et al., 2015) indicating slower advance of the thawing front and thus limiting the amount of water infiltration in the ground. The decrease of VWC during the summer is consistent with the active layer thickening period. Finally, although the surface aspect at Cime Bianche is more or less similar than at Schilthorn, differences in soil granulometry (more fine grained material and lower hydraulic conductivity) could also affect the evolution of the VWC.

The VWC evolution at Gemmi shows typical characteristics of seasonal frost conditions in (partly organic) soil, i.e., high water contents in summer, short winter minimum and marked transition phases. The large difference in absolute values during the summer period (around $50 \%$ at $10 \mathrm{~cm}$, and around $35 \%$ at 30 and $50 \mathrm{~cm}$ depth) can be explained by the presence of a $15 \mathrm{~cm}$ thick organic layer, which is capable to store much larger quantities of water than the underlying mineral soil. The two transition phases (zero-curtain) are observed when the temperature reaches the freezing point and remains constant until all the ground is thawed (respectively frozen). At Gemmi these periods are longer than at Schilthorn and Cime Bianche/Cervinia especially at the beginning of the winter. Given that no permafrost is present, a one-sided freezing process takes place, characterized by water migrating toward the freezing front from below, prolonging the zero-curtain period. Furthermore, the VWC at $10 \mathrm{~cm}$ depth at the end of the summer period exhibits a two-step increase corresponding to the infiltration of melt water through a thinned snow cover in early April (first peak) followed by constant near-zero temperature. The second increase marks the end of the zero-curtain period and the total melt of the snow cover.

The site-dependent patterns of VWC temporal evolution observed at Schilthorn, Cervinia, and Gemmi are consistent with the site-specific ground properties, and demonstrate the general applicability of FDR monitoring sensors for VWC measurements at high elevation. However, the reliability of the absolute values also needs to be assessed since the measurements are used for the calibration procedure of Archie's law and as validation data for the COUP model results (see Figure 1). The site-specific calibration procedure at Schilthorn yielded coefficients $\left(r^{2}=\right.$ 0.92) almost identical to the ones found by Krauss et al. (2010) for the same sensors in soil with nearly the same composition. The same calibration procedure was also applied at Gemmi for the SMT100 and coefficients were found with a significant $r^{2}=0.89$.

\section{A-ERT}

The automatic ERT installation at Schilthorn (Hilbich et al., 2011) allows us to assess the evolution of the VWC spatial 
distribution at the near-surface. Figure 5 is limited to the summer 2009 but data available until 2015 show that the spatial distribution observed in 2009 is found every year although the absolute values may vary. Thus the spatial repartition of VWC at Schilthorn is the result of constant subsurface properties and/or runoff conditions similar from 1 year to the next. Indeed the drier area of the profile (Figure 5A, zone a) is located where the weathered material layer is relatively thin and below a relatively small snow patch. In contrast, the wetter area (Figure 5A, zone b) is underlined by a thicker layer of weathered material and the snow patch above is larger and longer lasting.

The simultaneous VWC increase over the whole profile is also seen in the years following 2009 but its onset can vary between end of May and middle of June. This increase of VWC corresponds to a large snow melt water infiltration events and marks the start of the zero-curtain period $\left(\mathrm{T} \sim 0^{\circ} \mathrm{C}\right)$, which is more or less simultaneous over the whole profile (see Hilbich et al., 2011). The second increase in VWC observed in the measured data (Figure 5B) is most probably due to the end of the zero-curtain period $\left(T>0^{\circ} \mathrm{C}\right)$ and the total melt out of the snow cover. This happens typically later in the season (end of June to middle of July). More details on the interactions between ground temperature, apparent resistivity and soil moisture for the summer 2009 at Schilthorn can be found in Hilbich et al. (2011).

The calibration of Archie's law using the measured VWC is robust $\left(\mathrm{RMSE}=2.2 \%, r^{2}=0.7\right)$. The same calibration procedure applied to a second FDR monitoring sensor located $3 \mathrm{~m}$ to the right along the ERT profile yielded almost identical parameters $\left(\rho_{\mathrm{W}}=55, m=1.87\right.$, and $n=1.56$, cf. Table 2$)$ with comparable accuracy (RMSE $=2.86 \%$ and $r^{2}=0.67$ ). Part of the observed bias in the calibration may be due to the lateral offset of the two FDR monitoring sensors used for this study (located one meter aside from the ERT monitoring line). Additionally, imprecisions in the measured absolute values of VWC due to the temperature dependency of the sensors and their given accuracy could also explain part of it.

\section{Four-Phase Model \\ Four-Phase Model Calibration}

The application of the 4PM at our three field sites yielded results that are in good agreement with field observations and other data, such as borehole temperatures. The absolute reliability of the modeled phase contents is however difficult to assess. Borehole temperatures and porosity measures can be used to qualitatively assess the accuracy of the 4PM at given locations but quantitative calibration would only be possible with measured ice-, water-, or air contents, which are usually not available.

At Cervinia, borehole drilling logs are available and show a layer of weathered material with a thickness of $2.5 \mathrm{~m}$ at the shallow borehole (SH), and $1 \mathrm{~m}$ at the deep borehole (DP). This is in pretty good agreement with the 3PM-dependent porosity model which calculates $55 \%$ at the surface near $\mathrm{SH}$ and $35 \%$ at $2.5 \mathrm{~m}$ depth. The modeled surface porosity at DP is with $36 \%$ significantly lower, which matches well with the differences observed in the drilling logs. The availability of borehole temperatures further allows the comparison of measured and modeled ALT at Schilthorn and Cervinia. At both sites measured and modeled ALT agree well (see Figure 7), except for the shallow borehole $\mathrm{SH}$ at Cervinia, where the active layer depth is overestimated by the 4PM. From the borehole data we can therefore state that the $4 \mathrm{PM}$ has a tendency to overestimate the porosity at the surface and underestimate the ALT (except at Cervinia at $\mathrm{SH}$ ).

The available soil moisture data for all three sites are so far unique data sets for quantitative calibration of the 4PM at the surface. In Figures 8A-D measured surface VWC (black) is compared temporally (FDR monitoring) and spatially (S-FDR) to the 4PM-derived VWC (red) for Schilthorn, Cervinia, and Gemmi. Additionally, the agreement between measured (S-FDR) and modeled (4PM) values is displayed for each site and approach in Figures 8E-H.

In terms of absolute values, the model performs quite well at Schilthorn and Cervinia with RMSE of 4.6 and 7.1\% respectively. At Gemmi the RMSE is with (30.5\%) very high and the model clearly underestimates the soil moisture along the whole profile. Globally, the measured in situ data exhibits much larger spatial and temporal variability, which was not obtained with the 4PM. Except for Gemmi, no systematic bias could be found between the modeled and the measured data. The smoother results of the 4PM origins in the diffusive nature of geoelectrical measurements as well as in the smoothing constraints applied during the geoelectrical inversions. This is in good accordance to the observation made for the A-ERT derived VWC values in Results Section A-ERT.

The 4PM calibration procedure presented in this study represents a significant improvement of the model. It automatically determines the values of the key parameters $\left(\phi, \rho_{\mathrm{W}}, m\right.$, and $\left.n\right)$ using surface VWC measurements without requiring any a-priori knowledge of the subsurface. Although, the absolute values of the modeled porosity at the surface need to be adjusted to more realistic values (see Results Section Four-Phase Model), the automatic calibration and porosity calculation is able to highlight lateral structures at depth thus better constrain the porosity. Also, care has to be taken when using FDR measurements as calibration data, since the FDR data are indirect measurements that need to be calibrated too (without soil specific calibration $\pm 0.05 \mathrm{~m}^{3} / \mathrm{m}^{3}$ accuracy for spatial FDR (Delta-T Devices, 2011) and $\pm 0.03 \mathrm{~m}^{3} / \mathrm{m}^{3}$ for the monitoring FDR (Truebner, 2012; Campbell Scientific, 2014). Furthermore, spatial FDR measurements are only possible when at least $6 \mathrm{~cm}$ of fine material or soil is available. Thus, the measurements are not representative for the ground itself, but rather for the matrix filling voids between the blocks, which may also cause a higher VWC dynamics compared to ERT measurements.

\section{Four-Phase Model Phase Contents}

Considering the totality of the profile, the VWC distribution at all sites corresponds to the inverse of the ice content distribution (i.e., where ice rich zones are located, the VWC is small and vice versa). Besides the obvious thermal reason, this result is also due to the model construction, where Archie's law is used to calculate the VWC, and the obtained value is then further used to calculate the ice and air content (see Hauck et al., 2011). This reflects the good ability of ERT to differentiate between water and ice is very 

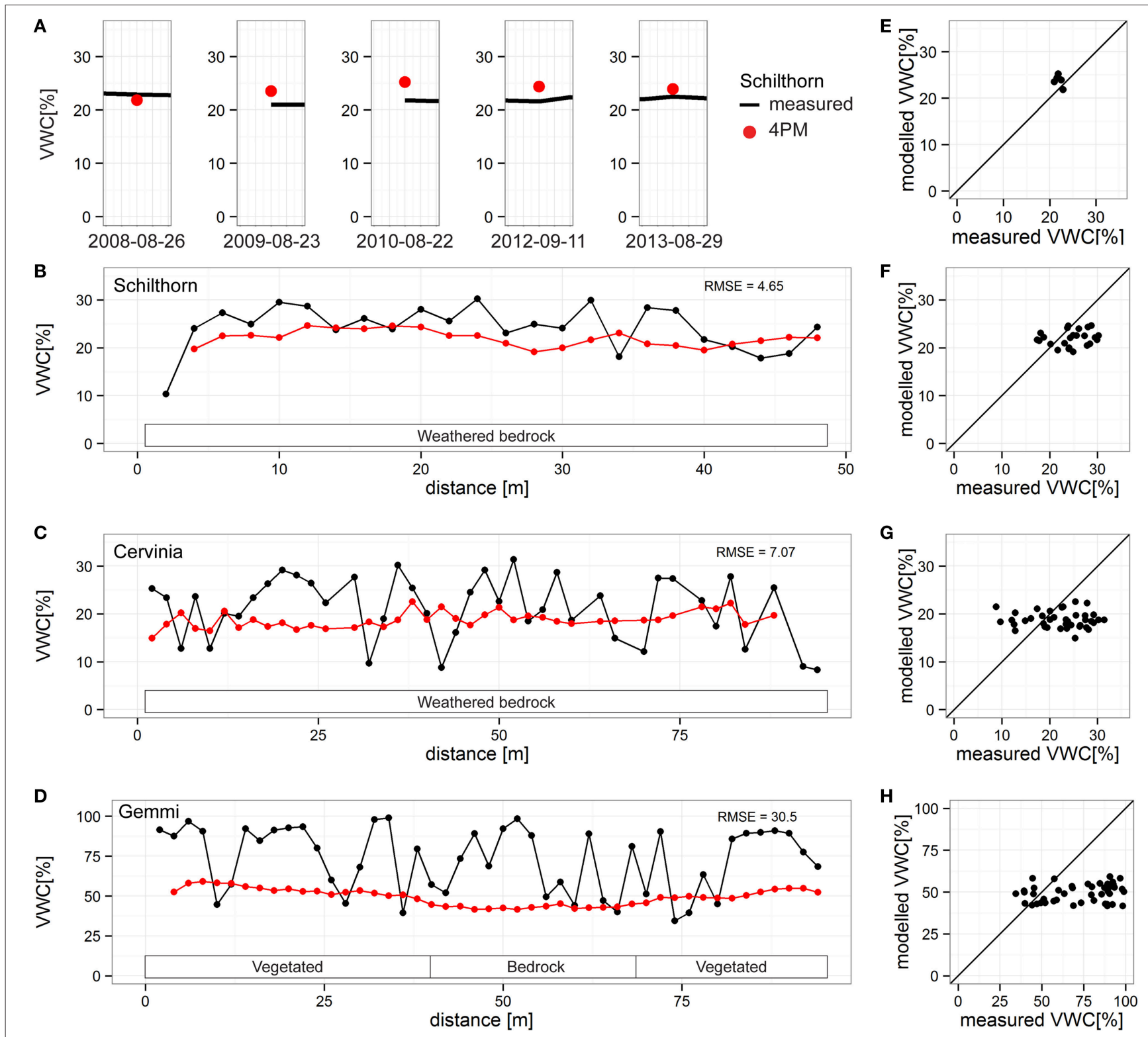

FIGURE 8 | Comparison of the modeled VWC (4PM) to the measured VWC (FDR) at Schilthorn (A,B), Cervinia (C), and Gemmi (D). The values of the uppermost model grid cells are compared to the spatial FDR measurements (B-D) and to the FDR monitoring sensors at different dates (A). The overall fit for each validation method is given in the right column (E-H).

clear. The accuracy of the VWC distribution at depth cannot be assessed with the temperature data as previously done for the ice content, since water and ice can coexist even at temperatures below $0^{\circ} \mathrm{C}$. Relative to the available pore space the $\mathrm{VWC}$ is increasing with depth. This is due to the decreasing porosity at depth. The absolute VWC (not shown) is rather constant throughout the whole profile at Schilthorn (around 20\%) and decreases at Cervinia and Gemmi (respective minimum around 10 and $15 \%)$.

The modeling of the ice content, which is of high interest in permafrost research, is much less reliable than for the VWC. The distinction between ice and rock is difficult to achieve with the used petrophysical relationships, given their similar geophysical properties $\left(v_{p}\right.$ and $\left.\rho\right)$. Thus, to correctly determine the ice content, the porosity needs to be well constrained. At all sites the maximum ice content values are found directly below the active layer and then slowly decreases with depth. Although, this can be a true feature due to the water migration toward the freezing front, which produces ice lenses and thus higher ice content at the bottom of the active layer, we think that it is an artificially introduced artifact due to the porosity gradient. Indeed, since ice and rock have similar geophysical properties, a decrease in 
porosity will be translated into a decrease in ice content in the model. However, the lateral variations of the active layer depth are in accordance with the measured borehole temperatures.

We think that the combined porosity model is an important improvement in the direction of better constrained porosity. However, given the integrated nature of the ERT and RST measurements no structures (e.g., cracks, karstic features, etc.) or features (e.g. ice lenses) smaller than the resolution of the geophysical measurements (depending on the sensor spacing, $\sim 1 \mathrm{~m}$ in the present case) can be reproduced in the porosity model. Furthermore, due to the smoothing effect of the inversion methods used for these two methods (ERT and RST) anisotropic structures such as vertical cracks are not always possible to identify. Depending on its orientation (along or across the path where electrical or seismic energy is transported) a fracture filled with air would not be observed at all or may appear as a strong resistive anomaly on the ERT profile (or lowvelocity anomaly in RST). Within each model grid cell of the 4PM $\left(0.5 \mathrm{~m}^{2}\right.$ resolution $)$ the microstructures of the ground are not represented, only the mean porosity of the grid cell is considered, which can explain the difficulties of the model to distinguish rock and ice at Gemmi.

Another improvement to the $4 \mathrm{PM}$ could be to use a different electrical mixing model, which includes the electrical conductivity of the rock, air and ice fractions. In that respect Python (2015) tested the application of the random electrical mixing model (e.g., Somerton, 1992) as well as a modified version of Archie's law including a rock conductivity term (after Sen et al., 1988) at one Alpine site where a highly conductive anomaly was present in the ERT, yielding promising results.

The Gemmi site was chosen to test the application of the 4PM in non-permafrost conditions. Given the site characteristics (altitude and mean annual air temperature) and the measurement date (end of August) unfrozen conditions can safely be assumed, although there is no borehole on site for confirmation. At Gemmi the 4PM modeled distribution of VWC at the surface is largely underestimated compared to the S-FDR measured values (cf. Figures $\mathbf{8 D}, \mathbf{H}$ ) and the RMSE is the largest among the three field sites (30.5\%). Furthermore, the application of the 4PM using the best-guess porosity model leads to the calculation of ice content $>0$ at depth (Figure 7J). Here the model reaches its limit for the distinction between ice and rock given the resistivity input data ( $5000 \Omega \mathrm{m}$ at $10 \mathrm{~m}$ depth and up to $50,000 \Omega \mathrm{m}$ at $20 \mathrm{~m}$ depth). The geological setting (massive limestone and karstic features with large air cavities) explains the high measured resistivity values but the 3PM-dependent porosity model is unable to reproduce this setting. At depth, the p-wave velocities are too high for the 4PM to model air (as we would expect), thus any change in porosity results in more or less ice content.

While the near-surface layers are well constrained, the modeling of phase content at greater depth is more problematic. Large areas of physically inconsistent solutions are observed at depth at Cervinia and Gemmi. It follows, that the parameters defined at the surface for these sites are not valid for the whole profile. Alternatively, large areas of physically inconsistent solutions at depth could also indicate inadequate porosity models. Finally, the 10,000 parameter combinations tested within the calibration procedure are randomly selected and not restricted to the physically consistent combinations.

\section{COUP Model}

The $4 \mathrm{PM}$ is a simple model, based on two geophysical datasets, which does not take into account the dynamics of the physical processes in the ground and it only has a temporal component if several ERT/RST datasets are available for different dates. To analyze the water and ice content evolution in detail we used the heat and mass transfer model COUP (see Scherler et al., 2010, 2013; Marmy et al., 2013). Due to the complexity of the coupled hydrological and thermal processes in the ground, we used here the semi-automated calibration scheme proposed by Marmy et al. (2015). The calibration only uses the borehole temperatures from SCH_5198 in order to have the measured soil moisture data as independent validation dataset. In a next step, these water contents, but also the measured resistivities, can be used to improve the calibration (see Python, 2015).

Here, we will focus our investigation on the assessment of the performance of the thermally calibrated COUP model (Marmy et al., 2015) to calculate water and ice content. For this study the semi-automated COUP model calibration procedure was completed by adjusting the porosity to match the best-guess porosity model used for the 4PM (see Table 3). The COUP model results were independently validated with the observed soil moisture values yielding a positive/negative bias of up to 30\% (see Marmy et al., 2015). This bias was substantially reduced by manually adjusting the wilting point without worsening the thermal calibration (Marmy et al., 2015). The wilting point parameter was selected for its part in the water retention function and its notable influence on the minimal residual water content in the ground (see Marmy et al., 2015). Figure 9 shows the temperature calibration (A, B, and $\mathrm{C}$ ) and the soil moisture validation after the wilting point adjustment for comparable depths (D, E, and F).

Both the temperatures and the VWC modeled by the COUP model show good agreement with the measured data, which means that a consistent simulation of these two variables at different depths is possible. Looking at the overall VWC evolution of the model, the typical seasonal phases observed in Results Section Soil Moisture Monitoring are reproduced and the absolute minimum and maximum values are coherent, although the variability of the modeled VWC is larger. The timing of the soil moisture increase and decrease is well constrained with the current calibration, since it is mainly driven by temperature. The finer tuning using measured soil moisture lead to an improvement of the temperature calibration (see Figure 10). At $0.2 \mathrm{~m}$ depth $r^{2}=0.706$ before tuning and $r^{2}=0.729$ afterwards.

TABLE 3 | Summary of the porosities used in the 4PM and COUP model.

\begin{tabular}{lccc}
\hline & $\boldsymbol{\Phi}_{\mathbf{0 - 2 m}}[\%]$ & $\boldsymbol{\Phi}_{\mathbf{2 - 5 m}}[\%]$ & $\boldsymbol{\Phi}_{\mathbf{5 - 3 0 m}}[\%]$ \\
\hline 4PM & $51-42$ & $42-30$ & $30-10$ \\
COUP & 46 & 36 & 10 \\
\hline
\end{tabular}

Measured $\Phi_{0.12-0.23 m}[\%]=53 \%$. 

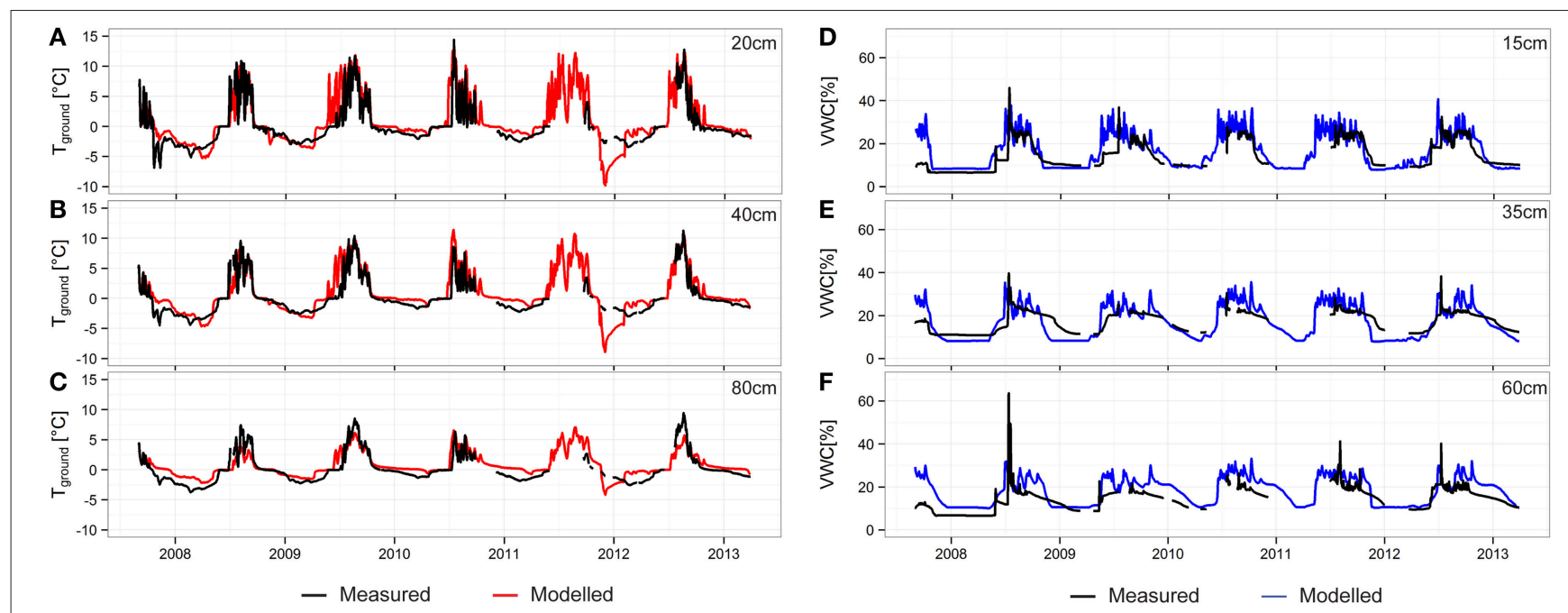

FIGURE 9 | Calibration of the COUP model at Schilthorn using measured ground temperature at several depths (A-C) and validation of the model using measured soil moisture (D-F) at similar depths.

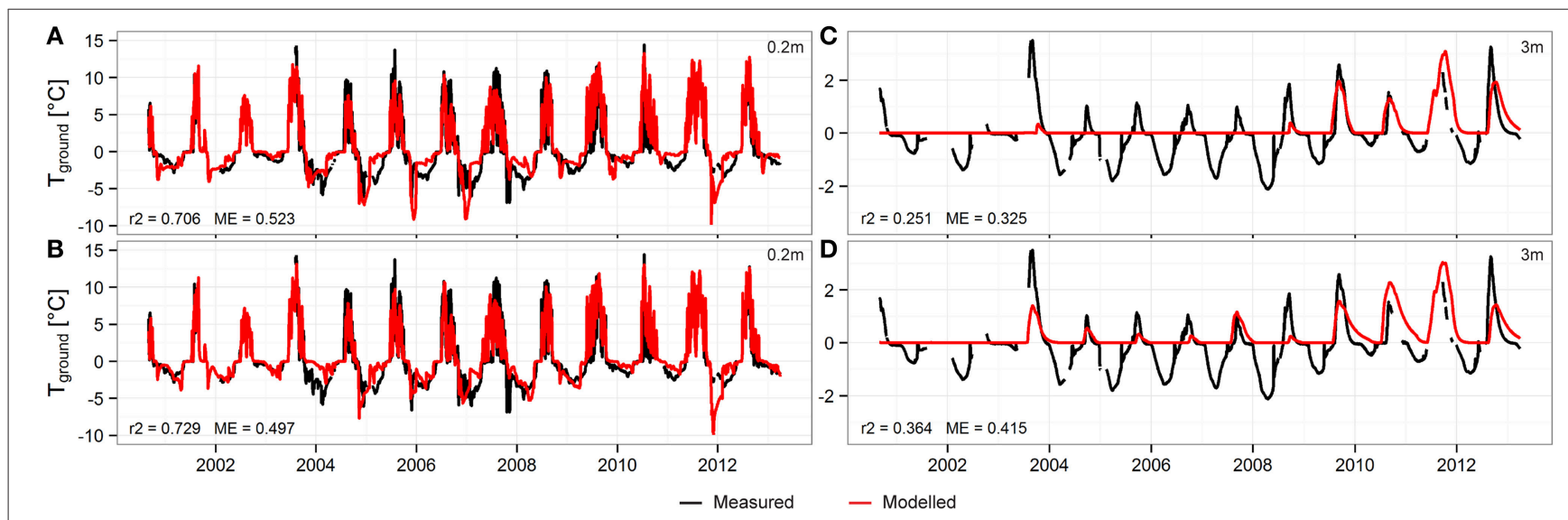

FIGURE 10 | Comparison of the COUP model semi-automated calibration of ground temperature before the manual adaptation of the wilting point (upper panel) and afterwards (lower panel). The calibration accuracy is tested at $20 \mathrm{~cm}$ (A,B) and $3 \mathrm{~m}$ depth (C,D).

Similarly, at $3 \mathrm{~m}$ depth $r^{2}=0.251$ before finer tuning and $r^{2}=$ 0.364 afterwards.

\section{Model Comparison}

The 4PM and the COUP model both yielded plausible VWC and ice content at Schilthorn using two very different approaches and input datasets. The two models are complementary: the $4 \mathrm{PM}$ produces a $2 \mathrm{D}$ snapshot in time of the VWC distribution in the ground whereas the COUP model shows the continuous temporal evolution of VWC within one soil column.

At Schilthorn 4PM simulations were conducted for several years $(2008,2009,2010$, and 2012) using the same calibration parameters as in Table 2 and the best-guess porosity model (Figure 7A). The water- and ice content values were then extracted at the location of the soil column corresponding to the COUP model. Given the different model compartment size, the porosity used in both models is slightly different (see Table 3), thus the distribution of water- and ice content per porosity are compared in Figure 11.

The 4PM and COUP model simulate very similar relative ice and water content values in the uppermost $5 \mathrm{~m}$ at Schilthorn, which corresponds more or less to the depth of the active layer. In both models an ice-free and comparatively moist layer is seen near the surface with slightly smaller water content in the 4PM compared to the COUP model. Below the active layer VWC values as simulated by the COUP model decrease strongly and ice content values increase proportionally almost reaching full saturation. On the other hand the 4PM-modeled VWC remains more or less constant and the ice content shows much smaller values, with a maximum saturation of the pore space of $27 \%$.

The different behavior of 4PM and COUP modeled water and ice content below the active layer can be partly explained by the geophysical input data. Indeed the ERT and RST data both contain inherent uncertainties due to the inversion 


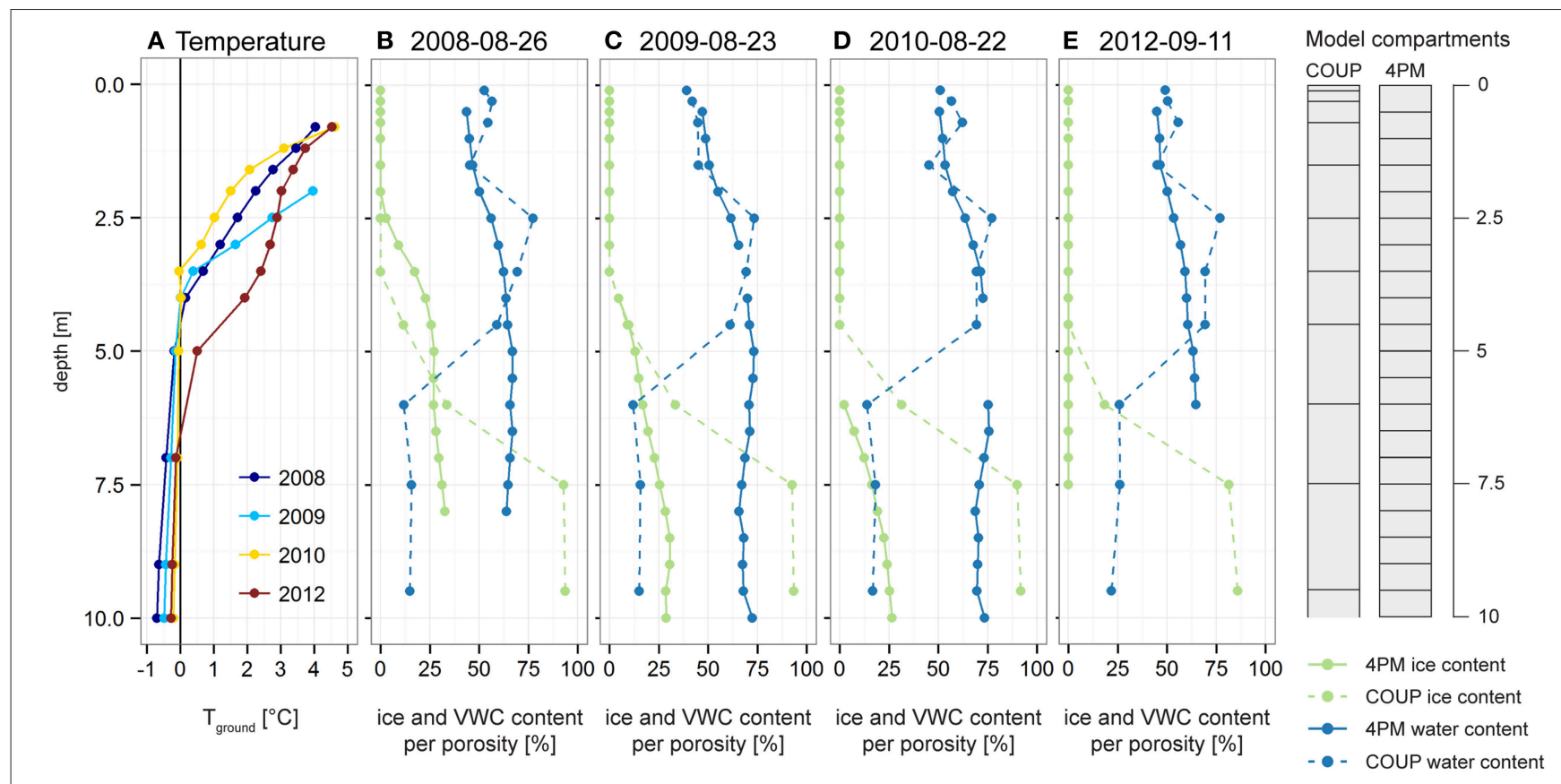

FIGURE 11 | Vertical distribution of borehole temperatures (A), water (blue lines) and ice (green lines) content per porosity modeled by the COUP model (dashed lines) and the 4PM model (solid lines) at Schilthorn (B-E). The COUP and 4PM model compartments are displayed on the right.

process. Hilbich et al. (2009) showed that, using Res2dinv for inversion, the inverted specific resistivities obtained below a highly conductive layer (e.g., a water saturated zone) can be greatly underestimated when a strong resistivity contrast is present. Furthermore, the RST inversion scheme applied here produces a very smooth velocity repartition in the ground (Figure 6B), without showing a sharp interface between frozen and unfrozen areas in the 4PM. Thus, the 4PM calculates higher VWC values below the active layer than the COUP model and contrastingly, the $4 \mathrm{PM}$ ice content is lower at the same depth.

Looking at the different years, there are no major differences except for the depth of the ice-free layer, both in the 4PM and the COUP model. The modeled active layer depths match quite well to the observed borehole temperatures (Figure 11A), with a slight underestimation in 2008 and overestimation in 2010/12. Furthermore the 4PM modeled ice content is consistent with the recorded temperatures. It is largest in 2008/09, which are the coldest year and in 2012, no ice is modeled by the 4PM, which fits with the significantly higher temperature and deeper active layer observed in the borehole. However, one has to be cautious not to over-interpret the inter-annual variations since the vertical resolution of $4 \mathrm{PM}$ is $50 \mathrm{~cm}$ whereas the COUP model vertical resolution decrease non-linearly with depth (cf. Figure 11 on the right).

\section{CONCLUSION}

In this study we presented a coherent methodology to assess the temporal evolution and spatial distribution of water and ice content at high elevation. Well established soil moisture monitoring techniques were combined with standard methods in mountain permafrost monitoring and the approach was tested at three field sites accounting for various ground properties, thermal regimes, and locations. Finally, the datasets were used to calibrate and validate two model approaches in permafrost research, in order to assess the ice content in the ground. The major results of the study can be summarized as follows:

The application of standard soil moisture measurement methods at high elevation area was shown to be reliable regarding the temporal evolution. The evolution observed in the measurements is consistent with the one expected in terrains undergoing seasonal freeze/thaw cycles. Furthermore, coupled with repeated ERT soundings, it was feasible to asses efficiently the temporal evolution of the spatial distribution. Thus, runoff regime and preferential flow paths could be identified.

The geophysically-based 4PM is still under development and different formulations for the petro-physical relationships are being tested but so far its application in permafrost area yields satisfactory results. The use of spatial soil moisture measurements as calibration data for the $4 \mathrm{PM}$ further constrained the model at the three sites used in this study. Furthermore, the development of 3PM-dependent and-independent porosity models constitutes a major improvement in the direction of more realistic porosity models. However, the application of the $4 \mathrm{PM}$ in unfrozen areas is still problematic. Depending on the subsurface properties and the input ERT data, ice occurrence can be simulated even in regions, where it is highly unlikely.

Similarly, the coupled heat and mass transfer model COUP was able to accurately reproduce the temporal evolution 
of soil moisture. The model was calibrated using a semiautomated calibration procedure based solely on measured ground temperature, and further improved by adjustments based on the soil moisture measurements. A next step would be to include the soil moisture data in the semi-automated calibration procedure and use the measured resistivity as independent validation (or vice versa).

\section{AUTHOR CONTRIBUTIONS}

$\mathrm{CP}$ collected and processed all data, performed the calculations relative to the water content and the $4 \mathrm{PM}$ modeling. She made all figures, wrote the major part of the text and developed the automatic 4PM calibration procedure with input from $\mathrm{CHi}$ and $\mathrm{CHa}$. $\mathrm{CP}, \mathrm{CHi}$, and $\mathrm{CHa}$ contributed to the elaboration of the methodology, the discussion of the results and the intermediate and final revision of the text.

\section{REFERENCES}

Albergel, C., Zakharova, E., Calvet, J.-C., Zribi, M., Parde, M., Wigneron, J.-P., et al. (2011). AS first assessment of the SMOS data in south western France using in situ and airborne soil moisture estimates: the CAROLS airborne campaign. Remote Sens. Environ. 115, 2718-2728. doi: 10.1016/j.rse.2011.06.012

Archie, G. E. (1942). The electrical resistivity log as an aid in determining some reservoir characteristics. Petrol. Trans. Am. Inst. Min. Metallur. Eng. 146, 54-62. doi: 10.2118/942054-G

Arenson, L., Hoelzle, M., and Springman, S. M. (2002). Borehole deformation measurements and internal structure of some rock glaciers in Switzerland. Permafr. Perigl. Proc. 13, 117-135. doi: 10.1002/ppp.414

Bircher, S., Balling, J. E., Skou, N., and Kerr, Y. H. (2012). Validation of SMOS brightness temperatures during the HOBE airborne campaign, Western Denmark. IEEE Trans. Geosci. Remote Sens. 50, 1468-1482. doi: 10.1109/TGRS.2011.2170177

Boike, J., Roth, K., and Ippisch, O. (2003). Seasonal snow cover on frozen ground: energy balance calculations of a permafrost site near Ny-Ålesund, Spitsbergen. J. Geophys. Res. Atmos. 108, 8163. doi: 10.1029/2001JD000939

Boike, J., Wille, C., and Abnizova, A. (2008). Climatology and summer energy and water balance of polygonal tundra in the Lena River Delta, Siberia. J. Geophys. Res. Biogeosci. 113, G03025. doi: 10.1029/2007JG000540

Brocca, L., Melone, F., Moramarco, T., and Morbidelli, R. (2010). Spatial-temporal variability of soil moisture and its estimation across scales. Water Res. Res. 46, W02516. doi: 10.1029/2009WR008016

Brunet, P., Clement, R., and Bouvier, C. (2010). Monitoring soil water content and deficit using Electrical Resistivity Tomography (ERT) a case study in the Cevennes area, France. J. Hydrol. 380, 146-153. doi: 10.1016/j.jhydrol.2009.10.032

Calamita, G., Brocca, L., Perrone, A., Piscitelli, S., Lapenna, V., Melone, F., et al. (2012). Electrical resistivity and TDR methods for soil moisture estimation in central Italy test-sites. J. Hydrol. 454, 101-112. doi: 10.1016/j.jhydrol.2012.06.001

Campbell Scientific (2014). CS616 and CS625 Water Content Reflectometers. Instruction Manual, Revison: 2/14.

Delta-T Devices (2011). ThetaProbe Soil Moisture Sensor Type ML2x User Manual $M L 2 x-U M-1.21$. Instruction Manual.

Dorigo, W. A., Wagner, W., Hohensinn, R., Hahn, S., Paulik, C., Xaver, A., et al. (2011). The International Soil Moisture Network: a data hosting facility for global in situ soil moisture measurements. Hydrol. Earth Syst. Sci. 15, 1675-1698. doi: 10.5194/hess-15-1675-2011

Engelhardt, M., Hauck, C., and Salzmann, N. (2010). Influence of atmospheric forcing parameters on modelled mountain permafrost
AM performed the COUP model calibration and simulations and wrote the corresponding methodological part of the paper.

\section{FUNDING}

The $\mathrm{PhD}$ thesis of $\mathrm{CP}$ is funded by the SNSF-project SOMOMOUNT (project no 143325).

\section{ACKNOWLEDGMENTS}

This study was conducted within the SOMOMOUNT project funded by the Swiss National Science Foundation (project no 143325). We are thankful to our colleagues from ARPA for providing the data relative to the Cime Bianche/Cervinia field site and to the PERMOS network for the temperature data from Schilthorn. evolution. Meteorol. Zeitschrift 19, 491-500. doi: 10.1127/0941-2948/20 $10 / 0476$

Entekhabi, D., Njoku, E. G., O’Neill, P. E., Kellogg, K. H., Crow, W. T., Edelstein, W. N., et al. (2010). The soil moisture active passive (SMAP) mission. Proc. IEEE 98, 704-716. doi: 10.1109/JPROC.2010.2043918

Guglielmin, M., and Vanuzzo, C. (1995). Studio della distribuzione del permafrost e delle relazioni con i ghiacciai della piccola età glaciale nell'alta valtournenche (Valle d'Aosta, Italia), Atti Ticinesi di Scienze della Terra 38, 119-127.

Harris, C., Arenson, L. U., Christiansen, H. H., Etzelmuller, B., Frauenfelder, R., Gruber, S., et al. (2009). Permafrost and climate in europe: monitoring and modelling thermal, geomorphological and geotechnical responses. Earth Sci. Rev. 92, 117-171. doi: 10.1016/j.earscirev.2008.12.002

Harris, C., Haeberli, W., VonderMuhll, D., and King, L. (2001). Permafrost monitoring in the high mountains of Europe: the PACE project in its global context. Permafr. Perigl. Process. 12, 3-11. doi: 10.1002/ppp.377

Hauck, C. (2001). Geophysical Methods for Detecting Permafrost in High Mountains. PhD thesis. ETHZ, Zürich.

Hauck, C. (2002). Frozen ground monitoring using DC resistivity tomography. Geophys. Res. Lett. 29, 12-1-12-4. doi: 10.1029/2002GL014995

Hauck, C. (2013). New concepts in geophysical surveying and data interpretation for permafrost terrain. Permafr. Perigl. Process. 24, 131-137. doi: 10.1002/ppp. 1774

Hauck, C., Bach, M., and Hilbich, C. (2008). A four-phase model to quantify subsurface ice and water content in permafrost regions based on geophysical data sets, in Proceedings of the 9th International Conference on Permafrost 2008 (Fairbanks, AK), 675-680.

Hauck, C., Böttcher, M., and Maurer, H. (2011). A new model for estimating subsurface ice content based on combined electrical and seismic data sets. Cryosphere 5, 453-468. doi: 10.5194/tc-5-453-2011

Hauck, C., and Kneisel, C. (2008). Applied Geophysics in Periglacial Environment. Cambridge: Cambridge University Press.

Hausmann, H., Krainer, K., Brueckl, E., and Ullrich, C. (2012). Internal Structure, ice content and dynamics of olgrube and kaiserberg rock glaciers (otztal Alps, Austria) determined from geophysical surveys. Austrian J. Earth Sci. 105, $12-31$.

Hilbich, C. (2010). Time-lapse refraction seismic tomography for the detection of ground ice degradation. Cryosphere 4, 243-259. doi: 10.5194/tc-4-243-2010

Hilbich, C., Fuss, C., and Hauck, C. (2011). Automated time-lapse ERT for improved process analysis and monitoring of frozen ground. Permafr. Perigl. Process. 22, 306-319. doi: 10.1002/ppp.732

Hilbich, C., Hauck, C., Hoelzle, M., Scherler, M., Schudel, L., Voelksch, I., et al. (2008). Monitoring mountain permafrost evolution using electrical resistivity tomography: a 7-year study of seasonal, annual, and long-term variations 
at Schilthorn, Swiss Alps. J. Geophys. Res. Earth Surface 113, F01S90. doi: 10.1029/2007JF000799

Hilbich, C., Marescot, L., Hauck, C., Loke, M. H., and Mäusbacher, R. (2009). Applicability of electrical resistivity tomography monitoring to coarse blocky and ice-rich permafrost landforms. Permafr. Perigl. Process. 20, 269-284. doi: $10.1002 /$ ppp. 652

Hillel, D. (2004). Introduction to Environmental Soil Physics. Amsterdam: Elsevier Academic Press.

Hinkel, K. M., Paetzold, F., Nelson, F. E., and Bockheim, J. G. (2001). Patterns of soil temperature and moisture in the active layer and upper permafrost at Barrow, Alaska: 1993-1999. Global Planet. Change 29, 293-309. doi: 10.1016/S0921-8181(01)00096-0

Huebner, R., Heller, K., Guenther, T., and Kleber, A. (2015). Monitoring hillslope moisture dynamics with surface ERT for enhancing spatial significance of hydrometric point measurements. Hydrol. Earth Syst. Sci. 19, 225-240. doi: 10.5194/hess-19-225-2015

Imhof, M., Pierrehumbert, G., Haeberli, W., and Kienholz, H. (2000). Permafrost Investigation in the Schilthorn Massif, Bernese Alps, Switzerland. Permafr. Perigl. Process. 11, 189-206. doi: 10.1002/10991530(200007/09)11:3<189::AID-PPP348>3.0.CO;2-N

Jansson, P.-E. (2012). Coupmodel: model use, calibration, and validation. Trans. Asabe 55, 1335-1344.

Jansson, P.-E., and Karlberg, L. (2004). Coupled Heat and Mass Transfer Model for Soil-Plant-Atmosphere Systems. Department of Civil and Environmental Engineering, Royal Institute of Technology, Stockholm.

Jansson, P. E., and Moon, D. S. (2001). A coupled model of water, heat and mass transfer using object orientation to improve flexibility and functionality. Environ. Model. Software 16, 37-46. doi: 10.1016/S1364-8152(00)00062-1

Kerr, Y. H., Waldteufel, P., Wigneron, J.-P., Delwart, S., Cabot, F., Boutin, J., et al. (2010). The SMOS mission: new tool for monitoring key elements of the global water cycle. Proc. IEEE 98, 666-687. doi: 10.1109/JPROC.2010.2043032

Kerr, Y. H., Waldteufel, P., Wigneron, J.-P., Martinuzzi, J. M., Font, J., and Berger, M. (2001). Soil moisture retrieval from space: the soil moisture and ocean salinity (SMOS) mission. IEEE Trans. Geosci. Remote Sens. 39, 1729-1735. doi: $10.1109 / 36.942551$

King, M., Zimmerman, R., and Corwin, R. (1988). Seismic and electrical properties of unconsolidated permafrost. Geophys. Prospect. 36, 349-364. doi: 10.1111/j.1365-2478.1988.tb02168.x

Kneisel, C., Hauck, C., Fortier, R., and Moorman, B. (2008). Advances in geophysical methods for permafrost investigations. Permafr. Perigl. Process. 19, 157-178. doi: 10.1002/ppp.616

Krauss, L., Hauck, C., and Kottmeier, C. (2010). Spatio-temporal soil moisture variability in Southwest Germany observed with a new monitoring network within the COPS domain. Meteorol. Zeitschr. 19, 523-537. doi: 10.1127/09412948/2010/0486

Krummenacher, B., and Budmiger, K. (1992). Monitoring of periglacial phenomena in the Furggentalti Swiss Alps. Permafr. Perigl. Process. 3, 149-155. doi: 10.1002/ppp.3430030213

Krummenacher, B., Mihajlovic, D., Nussbaum, A., and Staub, B. (2008). 20 Jahre Furggentälti - Permafrostuntersuchungen auf der Gemmi. Bern: Geographica Bernensia.

Loke, M. H. (2006). RES2DINV ver 3.55 Rapid 2-D Resistivity \& IP Inversion using the Least-Squares Method, User Manual.

Magagi, R., Berg, A. A., Goita, K., Belair, S., Jackson, T. J., Toth, B., et al. (2013). Canadian experiment for soil moisture for soil moisture in 2010 (CanExSM10): overview and preliminary results. IEEE Trans. Geosci. Geosci. Remote Sens. 51, 347-363. doi: 10.1109/TGRS.2012.2198920

Marmy, A., Rajczak, J., Delaloye, R., Hilbich, C., Hoelzle, M., Kotlarski, S., et al. (2015). site-specific modelling of mountain permafrost evolution in Switzerland using a semi-automated calibration method. Cryosphere Discuss. 9, 4787-4843. doi: 10.5194/tcd-9-4787-2015

Marmy, A., Salzmann, N., Scherler, M., and Hauck, C. (2013). Permafrost model sensitivity to seasonal climatic changes and extreme events in mountainous regions. Environ. Res. Lett. 8:035048. doi: 10.1088/1748-9326/8/3/035048

Mittelbach, H., Casini, F., Lehner, I., Teuling, A. J., and Seneviratne, S. I. (2011). Soil moisture monitoring for climate research: evaluation of a low-cost sensor in the framework of the Swiss soil moisture experiment (SwissSMEX) Campaign. J. Geophys. Res. Atmos. 116:D05111. doi: 10.1029/2010JD014907
Mittelbach, H., Lehner, I., and Seneviratne, S. I. (2012). Comparison of four soil moisture sensor types under field conditions in Switzerland. J. Hydrol. 430, 39-49. doi: 10.1016/j.jhydrol.2012.01.041

Monnier, S., Camerlynck, C., Rejiba, F., Kinnard, C., Feuillet, T., and Dhemaied, A. (2011). Structure and genesis of the thabor rock glacier (Northern French Alps) determined from morphological and ground-penetrating radar surveys. Geomorphology 134, 269-279. doi: 10.1016/j.geomorph.2011. 07.004

Monnier, S., and Kinnard, C. (2013). Internal structure and composition of a rock glacier in the andes (upper Choapa Valley, Chile) using borehole information and ground-penetrating radar. Ann. Glaciol. 54, 61-72. doi: 10.3189/2013AoG64A107

Noroozvalashedi, R., Ghahraman, N., and Irannejad, P. (2012). Evaluation of the COUP model simulation of soil moisture and temperature under maize canopy and bare soil. Iran. J. Soil Res. 26, 55-66.

Outcalt, S. I., Nelson, F. E., and Hinkel, K. M. (1990). The zero-curtain effect: heat and mass transfer across an isothermal region in freezing soil. Water Res. Res. 26, 1509-1516. doi: 10.1029/WR026i007p,01509

PERMOS (2013). Permafrost in Switzerland 2008/2009 and 2010/2011, Glaciological Report (Permafrost) No 10/11, Zürich.

Pogliotti, P., Guglielmin, M., Cremonese, E., Morra di Cella, U., Filippa, G., Pellet, C., et al. (2015). Warming permafrost and active layer variability at cime bianche, Western European Alps. Cryosphere 9, 647-661. doi: 10.5194/tc-9647-2015

Python, S. (2015). Technical Improvement of the 4.Phase Model to Better Assess the Ice, Water and Air Content Estimation in Permafrost Substrate. Case Study: MSc thesis, University of Fribourg, Stockhorn.

Rajczak, J., Kotlarski, S., Salzmann, N., and Schär, C. (2015). Robust climate scenarios for sites with sparse observations: a two-step bias correction approach. Int. J. Climatol. doi: 10.1002/joc.4417. [Epub ahead of print].

Rautiainen, K., Lemmetyinen, J., Pulliainen, J., Vehvilainen, J., Drusch, M., Kontu, A., et al. (2012). L-Band radiometer observations of soil processes in boreal and subarctic environments. IEEE Trans. Geosci. Remote Sens. 50, 1483-1497. doi: 10.1109/TGRS.2011.2167755

Richards, L. A. (1931). Capillary conduction of liquids through porous mediums. J. Appl. Phys. 1, 318-333. doi: 10.1063/1.1745010

Rings, J., and Hauck, C. (2009). Reliability of resistivity quantification for shallow subsurface water processes. J. Appl. Geophys. 68, 404-416. doi: 10.1016/j.jappgeo.2009.03.008

Rist, A., and Phillips, M. (2005). First results of investigations on hydrothermal processes within the active layer above alpine permafrost in steep terrain. Norsk Geografisk Tidsskrift 59, 177-183. doi: 10.1080/002919505100205744

Robinson, D. A., Campbell, C. S., Hopmans, J. W., Hornbuckle, B. K., Jones, S. B., Knight, R., et al. (2008). Soil moisture measurement for ecological and hydrological watershed-scale observatories: a review. Vadose Zone J. 7, 358-389. doi: $10.2136 /$ vzj2007.0143

Robock, A., Vinnikov, K. Y., Srinivasan, G., Entin, J. K., Hollinger, S. E., Speranskaya, N. A., et al. (2000). The global soil moisture data bank. Bull. Am. Meteorol. Soc. 81, 1281-1299. doi: 10.1175/15200477(2000)081<1281:TGSMDB > 2.3.CO;2

Rosset, E., Hilbich, C., Schneider, S., and Hauck, C. (2013). Automatic filtering of ERT monitoring data in mountain permafrost. Near Surface Geophys. 11, 423-433. doi: 10.3997/1873-0604.2013003

Roth, K., and Boike, J. (2001). Quantifying the thermal dynamics of a permafrost site near Ny-Ålesund, Svalbard. Water Res. Res. 37, 2901-2914. doi: 10.1029/2000WR000163

Samouelian, A., Cousin, I., Tabbagh, A., Bruand, A., and Richard, G. (2005). Electrical resistivity survey in soil science: a review. Soil Tillage Res. 83, 173-93, doi: $10.1016 /$ j.still.2004.10.004

Sandmeier, K. J. (2011). REFLEXW Version 6.0 WindowsTM 9x/NT/2000/XP/7Program for the Processing of Seismic, Acoustic or Electromagnetic Reflection, Refraction and Transmission Data. User Manual.

Scapozza, C., Baron, L., and Lambiel, C. (2014). Borehole logging in alpine periglacial talus slopes (Valais, Swiss Alps). Permafr. Perigl. Process. 26, 67-83. doi: 10.1002/ppp.1832

Scherler, M. (2006). Messung und Modellierung Konvektiver Warmetransportprozesse in der Auftauschicht von Gebirgs-Permafrost am Beispiel des Schilthorns. MSc thesis, University of Zürich. 
Scherler, M., Hauck, C., Hoelzle, M., and Salzmann, N. (2013). Modeled sensitivity of two alpine permafrost sites to RCM-based climate scenarios. J. Geophys. Res. Earth Surface 118, 780-794. doi: 10.1002/jgrf.20069

Scherler, M., Hauck, C., Hoelzle, M., Staehli, M., and Voelksch, I. (2010). Meltwater infiltration into the frozen active layer at an alpine permafrost site. Permafr. Perigl. Process. 21, 325-334. doi: 10.1002/ppp.694

Scherler, M., Schneider, S., Hoelzle, M., and Hauck, C. (2014). A two-sided approach to estimate heat transfer processes within the active layer of the Murtèl-Corvatsch rock glacier. Earth Surf. Dynam. 2, 141-154. doi: 10.5194/esurf-2-141-2014

Schlaeger, S., Huebner, C., and Becker, R. (2005). "Simple soil moisture probe for low-cost measurement applications," in Proceedings of the 6th Conference on Electromagnetic Wave Interaction with Water and Moist Substances, ISEMA (Weimar), 258-265.

Schneider, S., Daengeli, S., Hauck, C., and Hoelzle, M. (2013). A spatial and temporal analysis of different periglacial materials by using geoelectrical, seismic and borehole temperature data at Murtèl-Corvatsch, upper engadin, Swiss Alps. Geogr. Helv. 68, 265-280. doi: 10.5194/gh-68-265-2013

Schön, J. H. (2004). Physical Properties of Rocks, Vol. 8: Fundamentals and Principles of Petrophysics, 1st Edn. Oxford: Pergamon.

Sen, P. N., Goode, P. A., and Sibbit, A. (1988). Electrical conduction in clay bearing sandstones at low and high salinities. J. Appl. Phys. 63, 4832-4840. doi: $10.1063 / 1.340476$

Seneviratne, S. I., Corti, T., Davin, E. L., Hirschi, M., Jaeger, E. B., Lehner, I., et al. (2010). Investigating soil moisture-climate interactions in a changing climate: a review. Earth Sci. Rev. 99, 125-161. doi: 10.1016/j.earscirev.2010.02.004

Somerton, W. H. (1992). Thermal Properties and Temperature-Related Behavior of Rock/Fluid Systems. Amsterdam: Elsevier.

Stähli, M., Jansson, P. E., and Lundin, L. C. (1996). Preferential water flow in a frozen soil - a two-domain model approach. Hydrol. Process. 10, 1305-1316. doi: 10.1002/(SICI)1099-1085(199610)10:10<1305::AID-HYP462>3.0.CO;2-F

Staub, B., Marmy, A., Hauck, C., Hilbich, C., and Delaloye, R. (2015). Ground temperature variations in a talus slope influenced by permafrost: a comparison of field observations and model simulations. Geogr. Helv. 70, 45-62. doi: 10.5194/gh-70-45-2015

Timur, A. (1968). Velocity of compressional waves in porous media at permafrost temperatures. Geophysics 33, 584-595. doi: 10.1190/1.1439954

Truebner. (2012). SMT100 Soil Moisture Sensor. Fact Sheet.

Vereecken, H., Huisman, J. A., Bogena, H., Vanderborght, J., Vrugt, J. A., and Hopmans, J. W. (2008). On the value of soil moisture measurements in vadose zone hydrology: a review. Water Res. Res. 44, W00D06. doi: 10.1029/2008WR006829

Vonder Mühll, D., Hauck, C., and Lehmann, F. (2000). Verification of geophysical models in alpine permafrost using borehole information. Ann. Glaciol. 31, 300-306. doi: 10.3189/172756400781820057

Vonder Mühll, D., and Holub, P. (1992). Borehole logging in alpine permafrost, upper engadin, Swiss Alps. Permafr. Perigl. Process. 3, 125-132. doi: 10.1002/ppp.3430030209

Westermann, S., Boike, J., Langer, M., Schuler, T. V., and Etzelmueller, B. (2011). Modeling the impact of wintertime rain events on the thermal regime of permafrost. Cryosphere 5, 945-959. doi: 10.5194/tc-5-945-2011

Westermann, S., Lüers, J., Langer, M., Piel, K., and Boike, J. (2009). The annual surface energy budget of a high-arctic permafrost site on Svalbard, Norway. Cryosphere 3, 245-263. doi: 10.5194/tc-3-245-2009

Westermann, S., Wollschlaeger, U., and Boike, J. (2010). Monitoring of active layer dynamics at a permafrost site on Svalbard using multi-channel groundpenetrating radar. Cryosphere 4, 475-487. doi: 10.5194/tc-4-475-2010

Wollschlaeger, U., Gerhards, H., Yu, Q., and Roth, K. (2010). Multi-channel ground-penetrating radar to explore spatial variations in thaw depth and moisture content in the active layer of a permafrost site. Cryosphere 4, 269-283. doi: 10.5194/tc-4-269-2010

Wu, S. H., and Jansson, P.-E. (2013). Modelling soil temperature and moisture and corresponding seasonality of photosynthesis and transpiration in a boreal spruce ecosystem. Hydrol. Earth Sys. Sci. 17. 735-749. doi: 10.5194/hess-17735-2013

Xarpell, L. G., Koivusalo, H., Laurén, A., and Repo, T. (2010). Simulation of Soil Temperature and Moisture under Different Snow and Frost Conditions with COUP Model. Working Papers of the Finnish Forest Research Institute. 163,30 .

Conflict of Interest Statement: The authors declare that the research was conducted in the absence of any commercial or financial relationships that could be construed as a potential conflict of interest.

Copyright (c) 2016 Pellet, Hilbich, Marmy and Hauck. This is an open-access article distributed under the terms of the Creative Commons Attribution License (CC BY). The use, distribution or reproduction in other forums is permitted, provided the original author(s) or licensor are credited and that the original publication in this journal is cited, in accordance with accepted academic practice. No use, distribution or reproduction is permitted which does not comply with these terms. 